\title{
Article
}

\section{Synthesis, DNA Binding and Antitumor Evaluation of Styelsamine and Cystodytin Analogues}

\section{Hugo K. H. Fong and Brent R. Copp *}

School of Chemical Sciences, University of Auckland, Private Bag 92019, Auckland, New Zealand; E-Mail: hfon009@aucklanduni.ac.nz

* Author to whom correspondence should be addressed; E-Mail: b.copp@auckland.ac.nz; Tel.: +64-9-923-8284; Fax: +64-9-373-7422.

Received: 4 December 2012; in revised form: 16 January 2013 / Accepted: 21 January 2013 / Published: 28 January 2013

\begin{abstract}
A series of N-14 sidechain substituted analogues of styelsamine (pyrido[4,3,2-mn]acridine) and cystodytin (pyrido[4,3,2-mn]acridin-4-one) alkaloids have been prepared and evaluated for their DNA binding affinity and antiproliferative activity towards a panel of human tumor cell lines. Overall it was found that styelsamine analogues were stronger DNA binders, with the natural products styelsamines B and D having particularly high affinity $\left(K_{\text {app }} 5.33 \times 10^{6}\right.$ and $3.64 \times 10^{6} \mathrm{M}^{-1}$, respectively). In comparison, the cystodytin iminoquinone alkaloids showed lower affinity for DNA, but were typically just as active as styelsamine analogues at inhibiting proliferation of tumor cells in vitro. Sub-panel selectivity towards non-small cell lung, melanoma and renal cancer cell lines were observed for a number of the analogues. Correlation was observed between whole cell activity and clogP, with the most potent antiproliferative activity being observed for 3-phenylpropanamide analogues 37 and 41 (NCI panel average $\mathrm{GI}_{50} 0.4 \mu \mathrm{M}$ and $0.32 \mu \mathrm{M}$, respectively) with $\operatorname{cog} \mathrm{P} \sim 4.0-4.5$.
\end{abstract}

Keywords: marine natural products; styelsamine; cystodytin; pyridoacridine; DNA binding

\section{Introduction}

A diverse array of bioactive alkaloids isolated from marine sources contain the pyrido[4,3,2-mn]acridine scaffold [1]. While more structurally complex congeners are known, the simplest examples of such alkaloids are the tetracyclic cystodytins $A-K(\mathbf{1}-\mathbf{1 1})$ and styelsamines A-D 
(12-15) (Figure 1). The cystodytins, isolated from ascidians Cystodytes dellechiajei (1-9) [2,3], Cystodytes sp. (10) [4] and Lissoclinum notti (11) [5] possess the alkaloidal skeleton in the iminoquinone oxidation state, with modifications at either C-12 or N-14 of the ethylamine sidechain. Cytotoxicity towards murine or human tumor cell lines has been reported for the family of alkaloids, with $\mathrm{IC}_{50}$ values of $0.6 \mu \mathrm{M}$ (L12010 murine lymphoma, 1/2), $0.6 \mu \mathrm{M}(\mathrm{L} 1210,3), 2.9 \mu \mathrm{M}$ (L1210, 4/5), $0.18 \mu \mathrm{M}$ (L1210, 6/7), 0.12 $\mu \mathrm{M}$ (L1210, 8/9), $1.6 \mu \mathrm{M}$ (HCT-116 human colon, 10), and $1.3 \mu \mathrm{M}$ (P388 murine leukemia, 11) suggesting some influence of $C-12$ substitution on potency. Styelsamines A-D (12-15) were isolated as cytotoxic constituents of the Indonesian ascidian Eusynstyela latericius [6]. Moderate cytotoxicity towards the HCT-116 human colon tumor cell line with $\mathrm{IC}_{50}$ values of 33, 89, 2.6 and $1.6 \mu \mathrm{M}$ were observed for each of 12-15 respectively. Styelsamine D is considered to play a central role in the biogenesis of many pyridoacridine alkaloids [7], though no definitive biosynthetic studies have been reported to date [8].

Figure 1. Structures of cystodytin and styelsamine natural products.

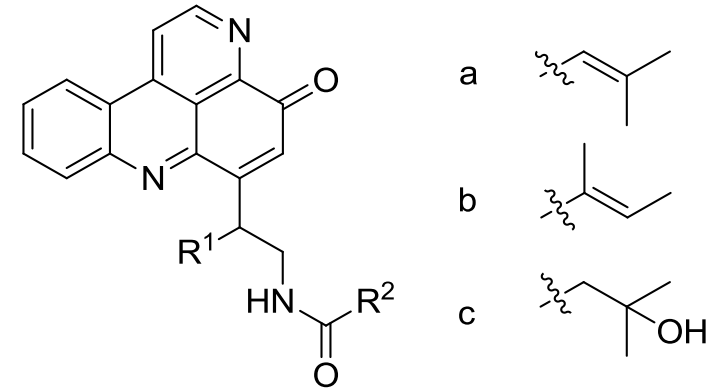

1 cystodytin $A R^{1}=H, R^{2}=a$

2 cystodytin $B R^{1}=H, R^{2}=b$

3 cystodytin $C R^{1}=H, R^{2}=c$

4 cystodytin $D R^{1}=O H, R^{2}=a$

5 cystodytin $\mathrm{E} \mathrm{R}^{1}=\mathrm{OH}, \mathrm{R}^{2}=\mathrm{b}$

6 cystodytin $\mathrm{F} \mathrm{R}^{1}=\mathrm{OMe}, \mathrm{R}^{2}=\mathrm{a}$

7 cystodytin $\mathrm{G} \mathrm{R}^{1}=\mathrm{OMe}, \mathrm{R}^{2}=\mathrm{b}$

8 cystodytin $\mathrm{HR}^{1}=\mathrm{OCO}\left(\mathrm{CH}_{2}\right)_{7} \mathrm{CH}=\mathrm{CH}\left(\mathrm{CH}_{2}\right)_{7} \mathrm{Me}, \mathrm{R}^{2}=\mathrm{a}$

9 cystodytin I $\mathrm{R}^{1}=\mathrm{OCO}\left(\mathrm{CH}_{2}\right)_{7} \mathrm{CH}=\mathrm{CH}\left(\mathrm{CH}_{2}\right)_{7} \mathrm{Me}, \mathrm{R}^{2}=\mathrm{b}$

10 cystodytin $\mathrm{J} \mathrm{R}^{1}=\mathrm{H}, \mathrm{R}^{2}=\mathrm{Me}$

11 cystodytin $\mathrm{KR}^{1}=\mathrm{OMe}, \mathrm{R}^{2}=\mathrm{Me}$<smiles>[R]NCC([R])c1cc(O)c2nccc3c2c1Nc1ccccc1-3</smiles>

12 styelsamine $A R^{1}=O H, R^{2}=H$ 13 styelsamine $B R^{1}=H, R^{2}=A c$ 15 styelsamine $D R^{1}=R^{2}=H$<smiles>O=Cc1cc(O)c2nccc3c2c1Nc1ccccc1-3</smiles>

14 styelsamine $C$

Pyridoacridine and pyridoacridine alkaloids typically exhibit wide-ranging biological properties including cytotoxicity, antibacterial and antiviral activities [9]. While it is often speculated that the bioactivity of pyridoacridine alkaloids is attributable to DNA binding [9], it has been noted by others that such a correlation is compound specific [4]. In the specific case of the cystodytins and styelsamines, all of the natural products have been evaluated for cytotoxicity, exhibiting a range of potency $\left(\mathrm{IC}_{50} 0.12-2.9 \mu \mathrm{M}\right)$ [2-5] but only the DNA binding ability of cystodytin $\mathrm{J}(\mathbf{1 0})$ has been reported $\left(K_{\text {disp }} 54 \mu \mathrm{M}\right)$ [4]. As the natural products have only been evaluated against a limited range of tumor cell lines (e.g., murine lymphoma, murine leukemia and human colon) information is lacking as to the presence or not of any cell line selectivity for pyridoacridine alkaloids. 
In an effort to explore the influence of N-14 substitution on the observed biological activities of styelsamine and cystodytin alkaloids, we have prepared a library of natural and un-natural analogues and evaluated their DNA affinity, using an ethidium bromide displacement assay, and cytotoxicity towards a panel of human tumor cell lines.

\section{Results and Discussion}

\subsection{Chemistry}

The overall reaction sequence used to synthesize the target compounds is summarized in Scheme 1. This biomimetic method, first reported by Skyler and Heathcock [10] in their synthesis of styelsamine $\mathrm{B}$, utilizes oxidative coupling of functionalized dopamine analogues with kynuramine to yield the desired pyridoacridine and pyridoacridone skeletons.

Scheme 1. General reaction sequence for the preparation of styelsamine and cystodytin analogues.<smiles>[R]C(=O)NCCc1ccc(O)c(O)c1</smiles><smiles>[R]C(=O)NCCc1cc(O)c2nccc3c2c1Nc1ccccc1-3</smiles>

Kynuramine dihydrobromide was prepared using a slightly modified version of the procedure previously reported [10]. Tryptamine (16) was first protected by conversion to the methyl carbamate 17, achieved in $73 \%$ yield (Scheme 2 ).

Scheme 2. Preparation of kynuramine dihydrobromide 20. Reagents and conditions: (i) methyl chloroformate, EtOAc/ $\mathrm{NaOH}(1: 0.6), \mathrm{N}_{2}, \mathrm{RT}, 30 \mathrm{~min}, 73 \%$; (ii) $\mathrm{O}_{3}, \mathrm{AcOH}$, $0{ }^{\circ} \mathrm{C}$, then conc. $\mathrm{HCl}, \mathrm{N}_{2}, 40{ }^{\circ} \mathrm{C}, 1.5 \mathrm{~h}, 42 \%$ (18) and $10 \%$ (19); (iii) aq. $\mathrm{HCl}$, reflux, $4 \mathrm{~h}$, $66 \%$ over two steps; (iv) $\mathrm{HBr}$ sat. $\mathrm{AcOH}, \mathrm{N}_{2}, 80{ }^{\circ} \mathrm{C}, 18 \mathrm{~h}, 96 \%$.

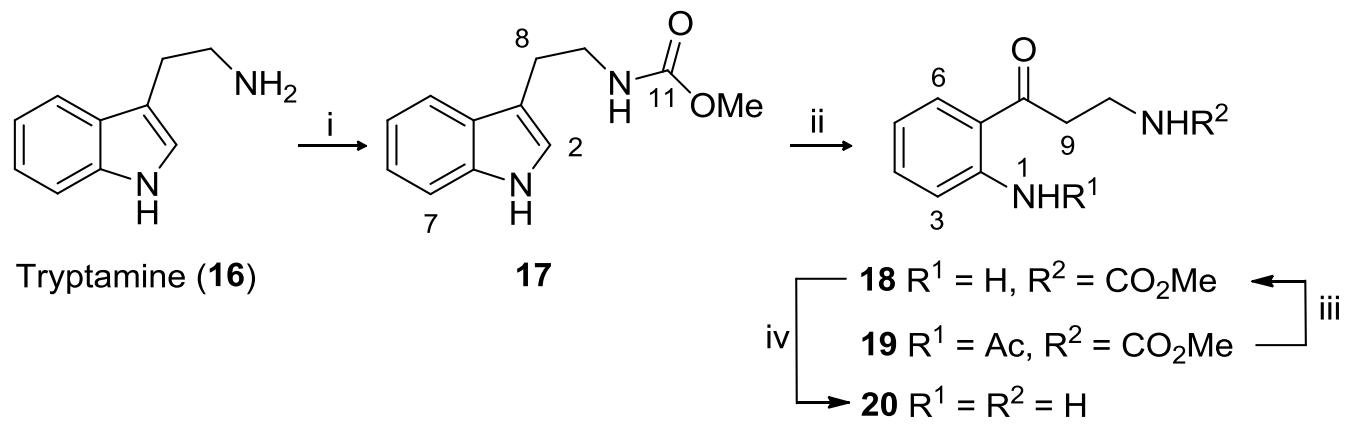

Whereas ozonolysis (in glacial acetic acid) of $\mathbf{1 7}$ has been previously reported to yield exclusively the keto-aniline 18, in our hands we also observed the presence of a minor product (10\% yield), determined to be the acetamide 19. Hydrolysis of the crude reaction product containing both $\mathbf{1 8}$ and 19 
in $10 \%$ aq. $\mathrm{HCl}$ afforded 18 (66\% yield over two steps) while subsequent reaction with $\mathrm{HBr}$ in $\mathrm{AcOH}$ cleaved the carbamate protecting group to afford kynuramine dihydrobromide (20) in $96 \%$ yield.

The requisite $N$-acyl dopamine analogues were prepared in two-step sequences from 3,4-dimethoxyphenethylamine (21) via one of three routes (Scheme 3). Thus acetamide 22 was synthesized in 95\% yield by reaction of 21 with acetic anhydride, amides $\mathbf{2 3}$ (92\%) and $\mathbf{2 5}$ (99\%) were prepared by reaction of $\mathbf{2 1}$ with the appropriate carboxylic acid using PyBOP as a coupling agent in DMF, while amides 24, 26 and 27 were prepared in yields of 57\%, 93\% and 65\% respectively by reaction of amine 21 with the appropriate acid chloride in $\mathrm{THF}$ with $\mathrm{Et}_{3} \mathrm{~N}$. Demethylation of 22-27 by reaction with $\mathrm{BBr}_{3}$ (10 equiv.) in dry $\mathrm{CH}_{2} \mathrm{Cl}_{2}$ for $19 \mathrm{~h}$ gave the desired $\mathrm{N}$-acyl dopamine analogues 28-33 in yields of $90 \%, 98 \%, 85 \%, 79 \%, 89 \%$, and $75 \%$, respectively.

Scheme 3. Synthesis of styelsamine $(\mathbf{1 3}, \mathbf{3 4 - 3 8})$ and cystodytin $(\mathbf{1}, \mathbf{1 0}, \mathbf{3 9}-\mathbf{4 2})$ analogues. Reagents and conditions: (i) for 22: $\mathrm{Ac}_{2} \mathrm{O}, \mathrm{N}_{2}, \mathrm{RT}, 1 \mathrm{~h}, 95 \%$; for 23 and 25: carboxylic acid, DMF, PyBOP, Et ${ }_{3} \mathrm{~N}, \mathrm{RT}, 18 \mathrm{~h}, 92 \%$ (23) and 99\% (25); for 24, 26 and 27: acyl chloride, THF, $\mathrm{Et}_{3} \mathrm{~N}, 0{ }^{\circ} \mathrm{C}$ rising to $\mathrm{RT}, 57 \%$ (24), 93\% (26), 65\% (27); (ii) $\mathrm{BBr}_{3}, \mathrm{CH}_{2} \mathrm{Cl}_{2}$, $\mathrm{N}_{2}$, -20 ${ }^{\circ} \mathrm{C}, 20$ h, 90\% (28), 98\% (29), 85\% (30), 79\% (31), 89\% (32), 75\% (33); (iii) kynuramine dihydrobromide (20), $\mathrm{CeCl}_{3} .7 \mathrm{H}_{2} \mathrm{O}, \mathrm{Ag}_{2} \mathrm{O}, \mathrm{MeOH} / \mathrm{AcOH}(2: 1), 19 \%$ (13), 6\% (34), 15\% (35), 11\% (36), 20\% (37), 16\% (38); (iv) $\mathrm{Ag}_{2} \mathrm{O}, \mathrm{MeOH}, 79 \%$ (10), 62\% (1), $52 \%$ (39), 13\% (40), 71\% (41), 17\% (42).

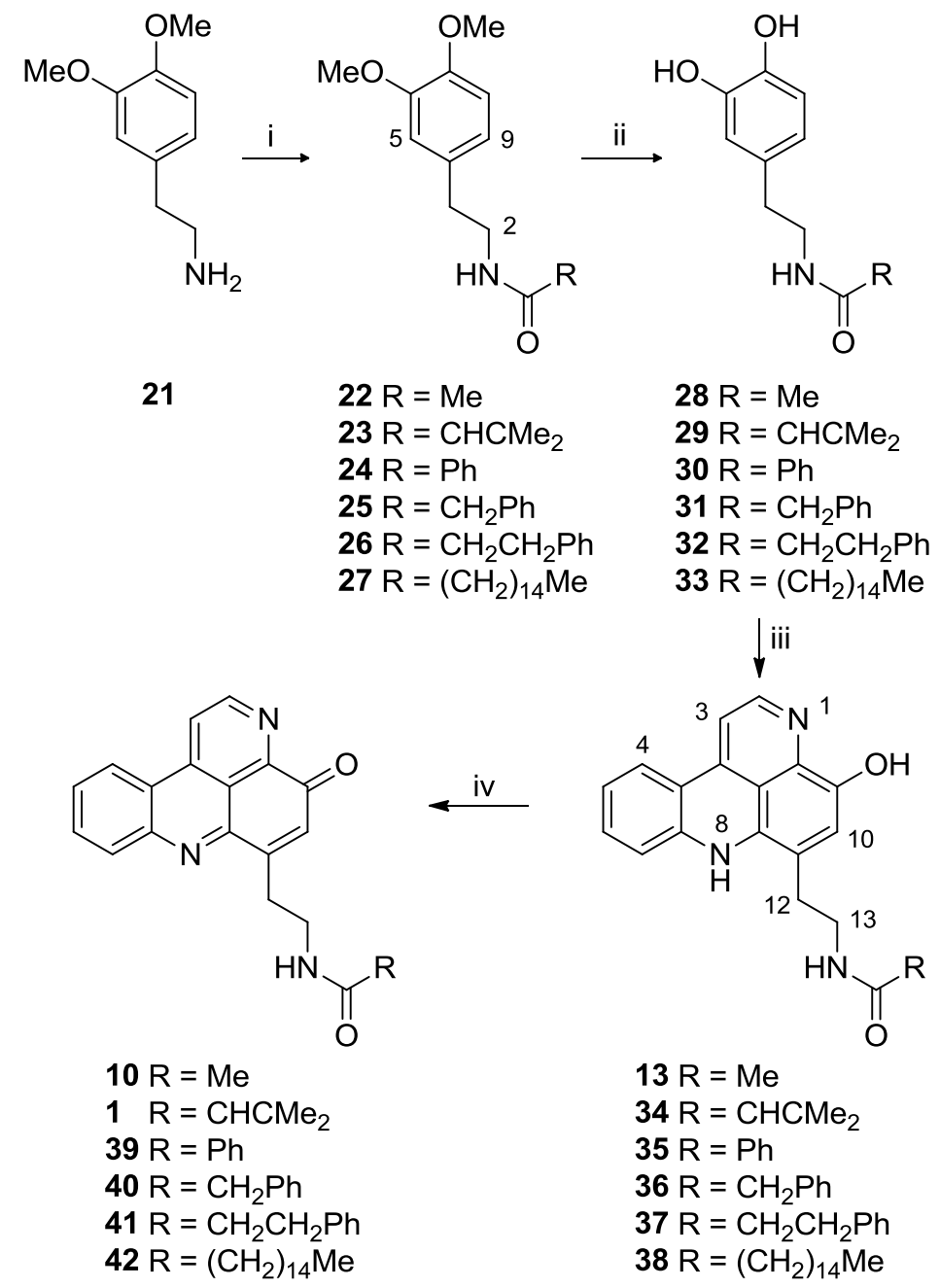


Using the general methodology reported by Skyler and Heathcock [10], reaction of the $\mathrm{N}$-acyldopamine analogues with kynuramine dihydrobromide (1.05 mole equiv.) in $\mathrm{MeOH} / \mathrm{AcOH}$ (2:1) to which were added $\mathrm{CeCl}_{3} \cdot 7 \mathrm{H}_{2} \mathrm{O}$ ( 0.15 mole equiv.) and silver (I) oxide ( 2 mole equiv.), afforded, after chromatographic purification, styelsamine B (13) and analogues 34-38 in yields of $19 \%, 6 \%, 15 \%, 11 \%, 20 \%$ and 16\% respectively (Scheme 3). In each case, high resolution ESI-MS gave a pseudomolecular ion consistent with the presence of the expected product of the reaction. The ${ }^{1} \mathrm{H}$ and ${ }^{13} \mathrm{C}$ NMR spectra of 13, 35-38 all contained the resonances expected for the styelsamine NH-1 to $\mathrm{CH}_{2}-13$ scaffold, with anticipated variation in NH-14 amide substitution. Data observed for $\mathbf{1 3}$ were in agreement with literature [6].

Each of the pyridoacridine alkaloids 13, 34-38 were then oxidized to the corresponding pyridoacridine analogue by reaction with $\mathrm{Ag}_{2} \mathrm{O}$ (1 equiv.) in $\mathrm{MeOH}$ with $\mathrm{NaHCO}_{3}$ (Scheme 3). The purple coloration of the aminophenol starting materials was observed to quickly convert ( $2 \mathrm{~min}$ ) to the yellow color of the iminoquinone chromophore. After workup, iminoquinones 10, 1, 39-42 were obtained in yields of $79 \%, 62 \%, 52 \%, 13 \%, 71 \%$, and $17 \%$, respectively.

For each of these products, ESI-MS identified a pseudomolecular ion two mass units lower than that observed for the corresponding pyridoacridine precursor. While complete NMR characterization of the reaction products was problematic due to their reduced solubility, evidence of successful formation of the iminoquinone scaffold was evidenced by changes in chemical shift of H-10. In the case of the aminophenol styelsamines, $\mathrm{H}-10$ is observed between $\delta_{\mathrm{H}} 7.14$ and 7.51, while for the iminoquinone cystodytins, H-10 resonates between $\delta_{\mathrm{H}} 6.81$ and 7.01. In the specific cases of 1 (cystodytin A) [2] and 10 (cystodytin J) [4], MS and NMR data agreed with those reported for the natural products.

It has been previously reported that heating styelsamine $\mathrm{B}$ (13) in $\mathrm{MeOH} / 4 \mathrm{~N} \mathrm{HCl}$ for $48 \mathrm{~h}$ yields the alkylamino analogue styelsamine D (15) in quantitative yield [7]. In our hands, repeating this reaction yielded not only 15 (60\%) but also a new $O$-methyl analogue 43 in $45 \%$ yield (Scheme 4 ).

Scheme 4. Synthesis of $O$-methylstyelsamine D (43) and amide analogues 46-48. Reagents and conditions: (i) $\mathrm{MeOH} / 4 \mathrm{~N} \mathrm{HCl} \mathrm{(1:1),} 80{ }^{\circ} \mathrm{C}, 48 \mathrm{~h}, 60 \%$ (15) and 45\% (43); (ii) for 46 and 47: $\mathrm{RCO}_{2} \mathrm{H}, \mathrm{CH}_{2} \mathrm{Cl}_{2}, \mathrm{Et}_{3} \mathrm{~N}, \mathrm{PyBOP}, 88 \%$ (46), 48\% (47); for 48 : dihydrocinnamoylchloride, THF, $\mathrm{Et}_{3} \mathrm{~N}, 30 \mathrm{~min}, 43 \%$.
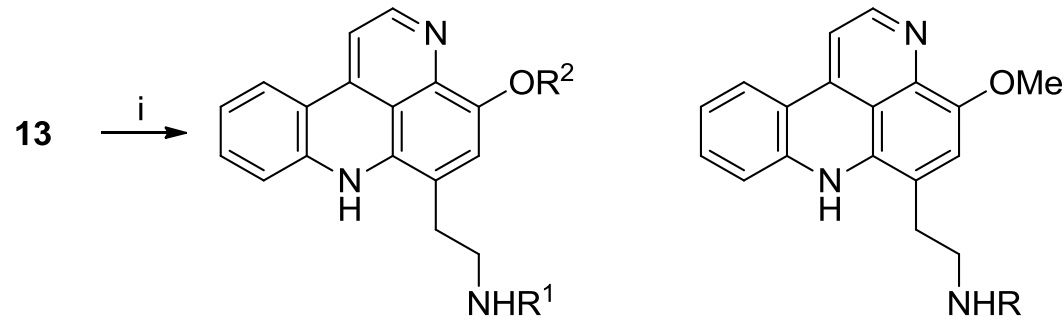

$$
\begin{aligned}
15 R^{1} & =R^{2}=H \\
43 R^{1} & =H, R^{2}=M e
\end{aligned}
$$

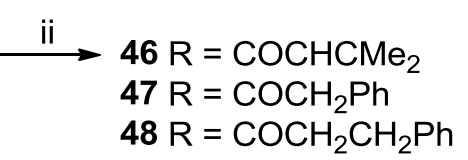

(+)-HRESI Mass spectrometric analysis of $\mathbf{4 3}$ identified a pseudomolecular ion at $\mathrm{m} / \mathrm{z} 292.1448$ $[\mathrm{M}+\mathrm{H}]^{+}$(calcd for $\mathrm{C}_{18} \mathrm{H}_{18} \mathrm{~N}_{3} \mathrm{O}, 292.1444$ ), being 14 mass units higher than styelsamine D 15. Detailed analysis of NMR data for $\mathbf{4 3}$ and comparison with those data observed for styelsamine D 
established the presence of an $O$-methyl group $\left[\delta_{\mathrm{H}} 4.06(3 \mathrm{H}, \mathrm{s}) ; \delta_{\mathrm{C}} 56.9\right]$ which was placed at $\mathrm{C}-11$ by observation of an HMBC correlation between $\delta_{\mathrm{H}} 4.06$ and $\delta_{\mathrm{C}}$ 138.7. These chemical shifts agree favorably with the corresponding sub-structural unit of nor-segoline (44) (Eudistoma sp.) [11] and arnoamine B (45) (Cystodytes sp.) [12] (Figure 2). Repeating the hydrolysis of styelsamine B, dissolved in $\mathrm{MeOH} / 4 \mathrm{~N} \mathrm{HCl}(1: 1)$, but heating at $80{ }^{\circ} \mathrm{C}$ for the shorter period of $24 \mathrm{~h}$ afforded styelsamine D 15 in $75 \%$ yield.

Figure 2. Structures of nor-segoline (44) and arnoamine B (45).<smiles>COc1cc(OC)c2nccc3c2c1Nc1ccccc1-3</smiles>

nor-segoline (44)<smiles></smiles>

arnoamine B (45)

With the unexpected synthesis of $\mathbf{4 3}$, the opportunity was taken to prepare a further subset of $N$-acyl analogues. Thus PyBOP-mediated reaction of $\mathbf{4 3}$ with the appropriate carboxylic acid in DMF afforded acrylamide 46 [2] (88\% yield) and 2-phenylacetamide 47 (48\% yield), while 3-phenylpropanamide 48 was prepared from 43 by reaction with dihydrocinnamoyl chloride in THF (43\% yield) (Scheme 4). For each of 46-48, the expected pseudomolecular ion was observed in high resolution ESI-mass spectrometry, and NMR data analysis revealed the expected resonances of the 11-O-methylstyelsamine scaffold with expected variation in the $\mathrm{NH}-14$ amide sidechain.

\subsection{Biological Activities}

Previous studies have shown that pyridoacridine alkaloids bind to DNA by a mechanism of base-pair intercalation [13,14]. In the present work, we made use of the fluorescence-based ethidium bromide displacement assay [15] to determine the apparent binding constant ( $\left.K_{\text {app }}\right)$ of the pyridoacridine and pyridoacridine alkaloids. The assay can also be used as an indicator for relative binding affinity, hence, ranking individual compounds. Ethidium bromide exhibits elevated fluorescence (at emission: $546 \mathrm{~nm}$; excitation: $595 \mathrm{~nm}$ ) when intercalated into DNA, but when displaced by a competing DNA binding agent the observed fluorescence decreases [15].

Using acetate buffer ( $\mathrm{pH}$ 5), the ability of each of the test compounds to displace ethidium bromide from calf thymus (CT) DNA was measured at a range of concentrations and the data interpolated to determine a $\mathrm{C}_{50}$ value (concentration required to reduce the fluorescence by $50 \%$ ) of each compound. The apparent binding constant $\left(K_{\text {app }}\right)$ was then calculated using the formula: $K_{\text {app }}=K_{\text {ethidium bromide }} \times$ $\left(1.26 / \mathrm{C}_{50}\right)$, where $K_{\text {ethidium bromide }}=2.1 \times 10^{6} \mathrm{M}(\mathrm{bp})^{-1}$ [16], in order to rank each compound according to their binding affinity (Table 1).

The results in Table 1 show that styelsamines B (13) and D (15) exhibit the highest affinity for CT-DNA within the styelsamine compound library, with $K_{\text {app }} 5.33 \times 10^{6}$ and $3.64 \times 10^{6} \mathrm{M}^{-1}$, respectively. Other styelsamine analogues were revealed to have mild to low affinity for CT-DNA, suggesting that the various sidechains hinder DNA binding. Reinforcing this point was the observation 
that the palmitamide analogue $\mathbf{3 8}$ exhibited the lowest DNA affinity of the styelsamine analogues. A similar trend was observed for the small library of $O$-methyl styelsamine analogues, with $O$-methyl styelsamine D (43) exhibiting a higher apparent binding constant, at $4.72 \times 10^{6} \mathrm{M}^{-1}$, compared to the other $N$-acyl analogues 46-48. In the case of the cystodytin library, natural products cystodytin A (1) and $J$ (10) exhibited slightly higher apparent binding constants than their un-natural analogues (entries 12-17). The cystodytin analogues were significantly less soluble in aqueous media than their styelsamine counterparts, with the iminoquinones typically requiring the addition of $0.5 \% \mathrm{DMSO}$ to facilitate dissolution. In the case of cystodytin J (10), addition of $0.5 \%$ DMSO to the sample yielded a slightly enhanced DNA binding affinity value (entries 13 and 14). The cystodytin palmitamide analogue 42 could not be solubilized, even with $0.5 \%$ DMSO, and so no DNA binding data could be determined.

Table 1. DNA binding affinities, antitumor activity and clogP values of styelsamine and cystodytin analogues.

\begin{tabular}{|c|c|c|c|c|c|c|}
\hline Entry & Compound & $\mathrm{C}_{50}{ }^{\mathrm{a}}$ & $K_{\text {app }} b$ & One dose $^{c}$ & $\mathbf{G I}_{50}{ }^{\mathrm{d}}$ & $\operatorname{clog} \mathrm{P}^{\mathrm{e}}$ \\
\hline 1 & 13 & $0.50 \pm 0.02$ & 5.33 & +34.3 & $3.2(2.0)$ & $2.6 \pm 0.4$ \\
\hline 2 & 15 & $0.73 \pm 0.02$ & 3.64 & +49.7 & $4.0(2.2)$ & $2.3 \pm 0.2$ \\
\hline 3 & $34^{\mathrm{f}}$ & $6.62 \pm 0.024$ & 0.40 & +36.6 & $3.2(2.4)$ & $3.6 \pm 0.5$ \\
\hline 4 & $35^{f}$ & $1.47 \pm 0.01$ & 1.80 & +10.5 & $0.63(1.9)$ & $4.1 \pm 0.4$ \\
\hline 5 & $36^{\mathrm{f}}$ & $4.10 \pm 0.47$ & 0.64 & $\mathrm{nt}^{\mathrm{g}}$ & & \\
\hline 6 & $37^{\mathrm{f}}$ & $1.67 \pm 0.19$ & 1.59 & -26.9 & $0.40(1.7)$ & $4.4 \pm 0.4$ \\
\hline 7 & $38^{f}$ & $35.1 \pm 1.3$ & 0.08 & +79.2 & inactive $^{\mathrm{h}}$ & $8.7 \pm 1.3$ \\
\hline 8 & 43 & $0.56 \pm 0.02$ & 4.72 & +24.1 & $1.6(1.3)$ & $2.7 \pm 0.3$ \\
\hline 9 & 46 & $5.43 \pm 0.15$ & 0.49 & +74.6 & inactive $^{\mathrm{h}}$ & $4.0 \pm 0.7$ \\
\hline 10 & $47^{\mathrm{f}}$ & $2.77 \pm 0.26$ & 0.95 & $\mathrm{nt}^{\mathrm{g}}$ & & \\
\hline 11 & 48 & $2.45 \pm 0.23$ & 1.08 & +45.6 & $3.2(2.0)$ & $4.7 \pm 0.7$ \\
\hline 12 & $1^{\mathrm{f}}$ & $11.1 \pm 0.3$ & 0.24 & +21.7 & $2.0(1.5)$ & $3.0 \pm 0.6$ \\
\hline 13 & 10 & $40.7 \pm 1.5^{\mathrm{g}}$ & 0.06 & +70.9 & inactive $^{\mathrm{h}}$ & $1.9 \pm 0.4$ \\
\hline 14 & $10^{f}$ & $16.0 \pm 0.2$ & 0.17 & & & \\
\hline 15 & $39^{f}$ & $78.2 \pm 4.6$ & 0.03 & +4.9 & $1.3(1.8)$ & $3.5 \pm 0.5$ \\
\hline 16 & $40^{f}$ & $24.8 \pm 0.6$ & 0.11 & $\mathrm{nt}^{\mathrm{g}}$ & & \\
\hline \multirow[t]{2}{*}{17} & $41^{\mathrm{f}}$ & $41.7 \pm 2.6$ & 0.06 & -14.8 & $0.32(2.0)$ & $3.8 \pm 0.6$ \\
\hline & propamidine & $29.1^{\mathrm{i}}$ & 0.09 & - & - & - \\
\hline
\end{tabular}

${ }^{\mathrm{a}} \mathrm{C}_{50}$ is defined as the drug concentration $(\mu \mathrm{M})$, which gives a $50 \%$ decrease in the fluorescence of bound ethidium bromide for an [ethidium bromide]:[DNA] molar ratio of 12.6:10. Average and standard error of 3 independent determinations are reported. ${ }^{\mathrm{b}}$ Apparent binding constant $\left(\times 10^{6} \mathrm{M}^{-1}\right)$; $K_{\text {app }}$ were calculated as

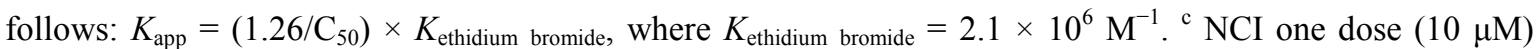
mean growth (\%). ${ }^{\mathrm{d}} \mathrm{GI}_{50}(50 \%$ growth inhibition) data $(\mu \mathrm{M})$ are averaged calculated mean values obtained from two experiments at the NCI. Value in parenthesis is the observed range of data, being the number of $\log 10$ units between the most and least sensitive cell line(s) in the panel. ${ }^{\mathrm{e}} \mathrm{cLogP}$ calculated using ALOGPS 2.1, as described in $[17,18] .{ }^{\mathrm{f}}$ Solution prepared in $0.5 \%$ DMSO/acetate buffer. ${ }^{\mathrm{g}}$ Not tested. ${ }^{\mathrm{h}}$ Inactive: preliminary one dose evaluation at the NCI indicated the compound was inactive. ${ }^{\text {i }}$ Literature value $23 \mu \mathrm{M}$ reported in [16]. 
The library of analogues was submitted to the NCI for evaluation against their panel of human tumor cell lines. Preliminary one dose $(10 \mu \mathrm{M})$ testing against 57 human tumor cell lines is summarized as a single value, the mean growth inhibition percentage over all cell lines, shown in Table 1. Of the styelsamine analogues 13, 15, 34, 35, 37, 38 (entries 1-7), 3-phenylpropanamide 37 was observed to be the most active, with the $10 \mu \mathrm{M}$ dose resulting in mean cell kill (negative growth). The remaining analogues were considered either mildly active, or inactive in the case of palmitamide 38. The corresponding $O$-methyl styelsamine analogues 43,46 and 48 exhibited moderate to poor growth inhibition (entries 8-11). Of the four cystodytin analogues tested (1, 10, 39, 41, entries 12-17), cystodytin J (10) was considered inactive, while the 3-phenylpropanamide analogue 41 was observed to be the most active. The wealth of data obtained from even this single dose testing afforded the ability to determine whether these alkaloids exhibit cell line specific activities. Sub-panel selectivity was observed for styelsamine B (13, more selective towards melanoma, non-small cell lung cancer, ovarian panels), styelsamine D (15, non-small cell lung cancer, CNS, renal), 34 (leukemia, renal), 35 (melanoma, renal), 37 (colon, melanoma, renal) and $\mathbf{3 8}$ (colon, renal) (see Supplementary Information). Although generally less potent, similar sub-panel selectivities were observed for the $O$-methyl styelsamine analogues [(43, non-small cell lung, renal); (46, non-small cell lung); (48, non-small lung cell, renal)]. In contrast, pyridoacridones 1, 10 and 39 were essentially non-selective, while 3-phenylpropanoid 41 exhibited selectivity towards colon, melanoma and renal cancer cell line sub-panels. The analogues that were considered active were then progressed to full 5-dose testing against the complete panel of cell lines, leading to determination of levels of activity corresponding to $50 \%$ growth inhibition $\left(\mathrm{GI}_{50}\right)$, total growth inhibition (TGI, cytostatic), or $50 \%$ lethality $\left(\mathrm{LC}_{50}\right)$. In general most compounds exhibited poor cytotoxicity, failing to reach $\mathrm{LC}_{50}$ or TGI levels of activity, and so only panel average $\mathrm{GI}_{50}$ values are reported in Table 1 . The $\mathrm{GI}_{50}$ values observed were in agreement with the relative activities observed in the one dose testing data, and similar sub-panel selectivities were also observed (data not shown). Thus styelsamine analogues 35 and $37\left(\mathrm{GI}_{50} 0.63 \mu \mathrm{M}\right.$ and $0.4 \mu \mathrm{M}$ respectively) and cystodytin analogue $41\left(\mathrm{GI}_{50} 0.32 \mu \mathrm{M}\right)$ were identified as the most potent tumor cell line growth inhibitors in this study.

While other groups have reported a direct relationship between cytotoxicity and DNA affinity of pyridoacridine alkaloids [13], the data presented in Table 1 suggests no such correlation between $K_{a p p}$ and $\mathrm{GI}_{50}$ value for the compounds in the present study. Styelsamines B (13), D (15) and analogue 34 all exhibited almost the same level of tumor cell growth inhibition $\left(\mathrm{GI}_{50} 3.2-4.0 \mu \mathrm{M}\right)$, whereas 13 and $\mathbf{1 5}$ bound approximately ten times more strongly to DNA than $\mathbf{3 4}$. Also of note is two alkaloids that exhibited approximately the same level of DNA affinity $\left(\mathbf{3 8}, K_{\text {app }} 0.08 \times 10^{6} \mathrm{M}^{-1} ; \mathbf{4 1}, 0.06 \times 10^{6} \mathrm{M}^{-1}\right)$ exhibited markedly different levels of antiproliferative activity (inactive and $\mathrm{GI}_{50} 0.32 \mu \mathrm{M}$ respectively). Cell penetration is clearly a requisite condition for molecules that exert biological activity by targeting DNA, with compound lipophilicity, $\log$ P, being a widely accepted descriptor of the ability of a drug to passively diffuse across a membrane. Log P was calculated for each of the test compounds, with the calculations being made using the ALOGPS 2.1 software package [17,18]. The software provides a range of calculated $\log \mathrm{P}$ values and the average with error is presented in Table 1. Plotting one dose mean cell growth inhibition activities against clogP (Figure 3) identified a correlation for both styelsamine and cystodytin alkaloids, with the best examples of growth inhibition 
occurring with alkaloid $\operatorname{cog} \mathrm{P} \sim 4.0-4.5$. Interestingly, no such correlation was observed for the, albeit small, data set of $O$-methyl styelsamine analogues 43,46 and 48 .

Figure 3. Plot of clogP vs mean cell growth (\%) of styelsamine, $O$-methyl styelsamine and cystodytin analogues.

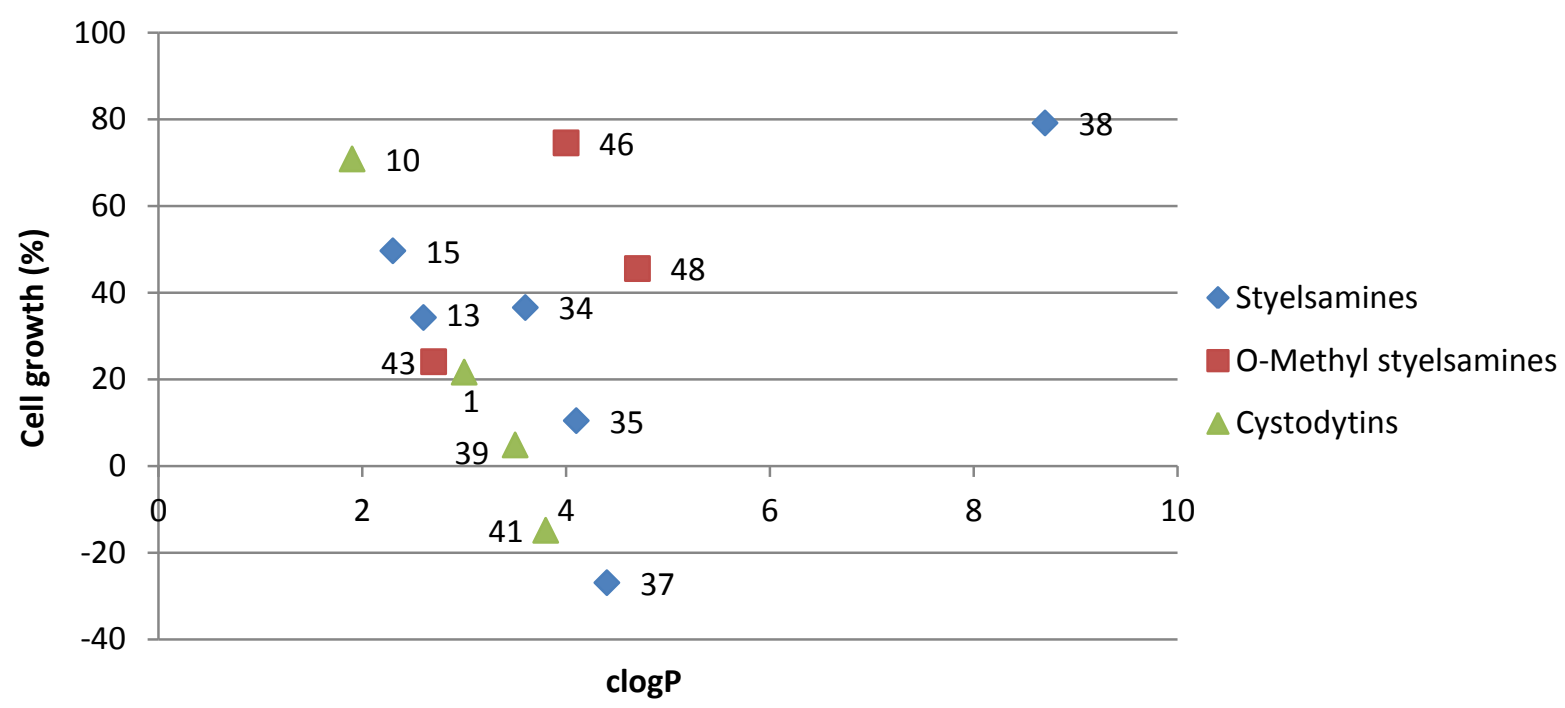

In summary, the current results have identified that natural and un-natural styelsamine and cystodytin analogues exhibit DNA affinity with the aminophenol styelsamines being the more potent series. Lipophilicity was found to be an important determinant of cell-based antiproliferative activity, with optimal activity being observed for alkaloids with clogP 4.0-4.5. The observation of enhanced antiproliferative activity associated with 3-phenylpropanamide analogues 37 and 41 suggests that sidechain modified analogues of styelsamines and/or cystodytins may have potential as new classes of antitumor agents.

\section{Experimental Section}

\subsection{General}

HRMS data were acquired on a Bruker micrOTOF-QII mass spectrometer. Infrared spectra were recorded on a Perkin-Elmer Spectrum 100 Fourier-transform IR spectrometer equipped with a universal ATR accessory. Ultraviolet-visible spectra were run as acetate buffer $(\mathrm{pH} 5)$ solutions either on a UV-2101 PC Shimadzu UV-VIS scanning spectrophotometer or a Perkin-Elmer Lambda 35 UV/VIS spectrometer. Fluorescence intensity was recorded on the Perkin-Elmer LS 55 Luminescence spectrometer. NMR spectra were recorded using a Bruker Avance DRX 400 spectrometer operating at $400 \mathrm{MHz}$ for ${ }^{1} \mathrm{H}$ nuclei and $100 \mathrm{MHz}$ for ${ }^{13} \mathrm{C}$ nuclei. Proto-deutero solvent signals were used as internal references (DMSO- $d_{6}: \delta_{\mathrm{H}} 2.50, \delta_{\mathrm{C}} 39.52 ; \mathrm{CDCl}_{3}: \delta_{\mathrm{H}} 7.25, \delta_{\mathrm{C}} 77.0 ; \mathrm{CD}_{3} \mathrm{OD}: \delta_{\mathrm{H}} 3.30, \delta_{\mathrm{C}} 49.05$ ). Analytical reversed-phase HPLC was run on a Dionex UltiMate 3000RS, using an Alltech platinum $\mathrm{C}_{18} 3 \mu \mathrm{m}$ column $(33 \times 7 \mathrm{~mm})$ and eluting with a linear gradient of $\mathrm{H}_{2} \mathrm{O}(0.05 \% \mathrm{TFA})$ to $\mathrm{MeCN}$ over $13.5 \mathrm{~min}$ at $2 \mathrm{~mL} / \mathrm{min}$. Flash column chromatography was performed using reversed-phase Merck Lichroprep RP-2 or RP-18, Kieselgel 60 PF silica gel, or by size exclusion chromatography on 
Pharmacia Biotech Sephadex LH-20. Thin layer chromatography used $0.2 \mathrm{~mm}$ thick plates of Kiesegel $\mathrm{F}_{254}$ (Merck, Manakau, New Zealand).

\subsection{Synthetic Procedures}

\subsubsection{Tryptamine Methyl Carbamate (17)}

To a stirred solution of tryptamine $(2.0 \mathrm{~g}, 0.01 \mathrm{~mol})$ in a degassed biphasic mixture of $\mathrm{NaOH}$ $(1 \mathrm{~N}, 12.5 \mathrm{~mL})$ and EtOAc $(20 \mathrm{~mL})$ was added methyl chloroformate $(1.01 \mathrm{~mL}, 13.13 \mathrm{mmol})$ dropwise, under $\mathrm{N}_{2}$. The brown solution was stirred for $30 \mathrm{~min}$ at room temperature, after which it was washed with $\mathrm{H}_{2} \mathrm{O}(2 \times 40 \mathrm{~mL})$ and the organic phase dried in vacuo. The residue was dissolved in EtOAc $(10 \mathrm{~mL})$ and then added to hexane $(50 \mathrm{~mL})$ to yield 17 as brown crystals $(2.47 \mathrm{~g}, 73 \%$ yield).

Mp 82.9-83.9 ${ }^{\circ} \mathrm{C}$ (lit. [19] 79.0-81.0 ${ }^{\circ} \mathrm{C}$ ); $R_{\mathrm{f}}$ (1 Hex:2 EtOAc) 0.64; IR $v_{\max }$ (ATR) 3400, 1686, 1544, $1264 \mathrm{~cm}^{-1} ;{ }^{1} \mathrm{H}$ NMR $\left(\mathrm{CDCl}_{3}, 400 \mathrm{MHz}\right) \delta_{\mathrm{H}} 8.02(1 \mathrm{H}$, br s, NH-1), $7.61(1 \mathrm{H}, \mathrm{d}, J=7.4 \mathrm{~Hz}, \mathrm{H}-4)$, $7.38(1 \mathrm{H}, \mathrm{d}, J=7.6 \mathrm{~Hz}, \mathrm{H}-7), 7.21(1 \mathrm{H}, \mathrm{td}, J=7.6,1.2 \mathrm{~Hz}, \mathrm{H}-6), 7.14(1 \mathrm{H}, \mathrm{td}, J=7.4,0.9 \mathrm{~Hz}, \mathrm{H}-5)$, $7.03(1 \mathrm{H}, \mathrm{d}, J=2.1 \mathrm{~Hz}, \mathrm{H}-2), 4.73(1 \mathrm{H}, \mathrm{br} \mathrm{s}, \mathrm{NH}-10), 3.65(3 \mathrm{H}, \mathrm{s}, \mathrm{OMe}), 3.53(2 \mathrm{H}, \mathrm{dt}, J=6.8,6.8 \mathrm{~Hz}$, $\left.\mathrm{H}_{2}-9\right), 2.98\left(2 \mathrm{H}, \mathrm{t}, J=6.8 \mathrm{~Hz}, \mathrm{H}_{2}-8\right) ;{ }^{13} \mathrm{C} \mathrm{NMR}\left(\mathrm{CDCl}_{3}, 100 \mathrm{MHz}\right) \delta_{\mathrm{C}} 157.1$ (C-11), $136.4(\mathrm{C}-7 \mathrm{a})$, 127.2 (C-3a), 122.2 (C-6 or C-2), 122.0 (C-6 or C-2), 119.4 (C-5), 118.7 (C-4), 112.9 (C-3), 111.2 (C-7), 52.0 (OMe), 41.2 (C-9), $25.8(\mathrm{C}-8)$; (+)-ESIMS m/z $219[\mathrm{M}+\mathrm{H}]^{+}$; (+)-HRESIMS [M + H] 219.1131 (calcd. for $\mathrm{C}_{12} \mathrm{H}_{15} \mathrm{~N}_{2} \mathrm{O}_{2}, 219.1128$ ). ${ }^{1} \mathrm{H}$ and ${ }^{13} \mathrm{C}$ NMR data agreed with literature [19].

\subsubsection{Kynuramine Methyl Carbamate (18) and N-Acetyl-kynuramine Methyl Carbamate (19)}

Ozone was bubbled into a solution of tryptamine methyl carbamate (17) (1.00 g, $4.59 \mathrm{mmol})$ in $\mathrm{AcOH}(20 \mathrm{~mL})$ that was stirred in an ice bath. The reaction was stopped once the solution became frozen. The frozen solution was degassed with $\mathrm{N}_{2}$ for $5 \mathrm{~min}$ and then conc. $\mathrm{HCl}(1 \mathrm{~mL})$ was added to the solution and warmed to $40{ }^{\circ} \mathrm{C}$ for $1.5 \mathrm{~h}$. After this time the solution was dried in vacuo, the residue dissolved in $\mathrm{CH}_{2} \mathrm{Cl}_{2}(20 \mathrm{~mL})$, and washed with phosphate buffer until neutral $(3 \times 20 \mathrm{~mL})$. The organic phase was dried $\left(\mathrm{MgSO}_{4}\right)$, solvent removed in vacuo and the mixture purified using silica gel flash chromatography (hexane/EtOAc) to afford kynuramine methyl carbamate $\mathbf{1 8}$ as a yellow solid (0.42 $\mathrm{g}, 42 \%$ yield) and 19 also as a yellow solid ( $0.13 \mathrm{~g}, 10 \%$ yield).

Kynuramine methyl carbamate 18: Mp 90.0-91.0 ${ }^{\circ} \mathrm{C}$ (lit. [20] 98.0-99.0 $\left.{ }^{\circ} \mathrm{C}\right) ; R_{\mathrm{f}}\left(10 \% \mathrm{MeOH} / \mathrm{CH}_{2} \mathrm{Cl}_{2}\right)$ 0.89; IR $v_{\max }$ (ATR) 3360, 1685, 1619, 1531, $1264 \mathrm{~cm}^{-1} ;{ }^{1} \mathrm{H} \mathrm{NMR}\left(\mathrm{CDCl}_{3}, 400 \mathrm{MHz}\right) \delta_{\mathrm{H}} 7.68(1 \mathrm{H}, \mathrm{d}$, $J=7.6 \mathrm{~Hz}, \mathrm{H}-6), 7.26(1 \mathrm{H}, \mathrm{dt}, J=7.6,1.6 \mathrm{~Hz}, \mathrm{H}-4), 6.65-6.61(2 \mathrm{H}, \mathrm{m}, \mathrm{H}-3$ and H-5), 3.64 (3H, s, $\mathrm{OMe}), 3.57\left(2 \mathrm{H}, \mathrm{dt}, J=5.6,5.6 \mathrm{~Hz}, \mathrm{H}_{2}-10\right), 3.17\left(2 \mathrm{H}, \mathrm{t}, J=5.6 \mathrm{~Hz}, \mathrm{H}_{2}-9\right) ;{ }^{13} \mathrm{C} \mathrm{NMR}\left(\mathrm{CDCl}_{3}, 100 \mathrm{MHz}\right)$ $\delta_{\mathrm{C}} 201.1(\mathrm{C}-8), 157.1$ (C-12), 150.4 (C-2), 134.6 (C-4), 131.0 (C-6), 117.7 (C-5), 117.4 (C-7), 115.9 (C-3), 52.0 (OMe), 38.9 (C-9), $36.2(\mathrm{C}-10)$; (+)-ESIMS m/z $223[\mathrm{M}+\mathrm{H}]^{+}$; (+)-HRESIMS [M + H] 223.1076 (calcd. for $\mathrm{C}_{11} \mathrm{H}_{15} \mathrm{~N}_{2} \mathrm{O}_{3}, 223.1077$ ).

$N$-Acetyl kynuramine methyl carbamate 19: Mp 120.0-121.0 ${ }^{\circ} \mathrm{C} ; R_{\mathrm{f}}(1 \mathrm{Hex}: 2 \mathrm{EtOAc}) 0.30$; IR $v_{\max }$ (ATR) 3332, 3220, 3112, 2947, 1700, 1686, 1544, 1292, 1195, $760 \mathrm{~cm}^{-1} ;{ }^{1} \mathrm{H} \mathrm{NMR}\left(\mathrm{CDCl}_{3}, 400 \mathrm{MHz}\right)$ $\delta_{\mathrm{H}} 11.62(1 \mathrm{H}$, br s, NH-1), $8.70(1 \mathrm{H}, \mathrm{d}, J=7.3 \mathrm{~Hz}, \mathrm{H}-3), 7.90(1 \mathrm{H}, \mathrm{d}, J=6.8 \mathrm{~Hz}, \mathrm{H}-6), 7.55(1 \mathrm{H}, \mathrm{td}$, $J=7.3,1.5 \mathrm{~Hz}, \mathrm{H}-4), 7.11(1 \mathrm{H}, \mathrm{td}, J=6.8,1.3 \mathrm{~Hz}, \mathrm{H}-5), 5.29(1 \mathrm{H}, \mathrm{br} \mathrm{s}, \mathrm{NH}-11), 3.66(3 \mathrm{H}, \mathrm{s}, \mathrm{OMe})$, 
$3.58\left(2 \mathrm{H}, \mathrm{dt}, J=5.6,5.6 \mathrm{~Hz}, \mathrm{H}_{2}-10\right), 3.29\left(2 \mathrm{H}, \mathrm{t}, J=5.6 \mathrm{~Hz}, \mathrm{H}_{2}-9\right), 2.23\left(3 \mathrm{H}, \mathrm{s}, \mathrm{H}_{3}-14\right) ;{ }^{13} \mathrm{C}$ NMR $\left(\mathrm{CDCl}_{3}, 100 \mathrm{MHz}\right) \delta_{\mathrm{C}} 203.4(\mathrm{C}-8), 169.4(\mathrm{C}-13), 157.0$ (C-12), 141.1 (C-2), 135.4 (C-4), 130.8 (C-6), 122.4 (C-5), 121.1 (C-7), 120.8 (C-3), 52.1 (OMe), 39.8 (C-9), 36.0 (C-10), 25.6 (C-14); (+)-ESIMS $m / z 265[\mathrm{M}+\mathrm{H}]^{+} ;(+)$-HRESIMS $[\mathrm{M}+\mathrm{H}]^{+} 265.1191$ (calcd. for $\mathrm{C}_{13} \mathrm{H}_{17} \mathrm{~N}_{2} \mathrm{O}_{4}, 265.1183$ ).

An alternative method to bypass the formation of acetamide $\mathbf{1 9}$ was to take the crude reaction product containing both $\mathbf{1 8}$ and 19, dissolve it in aq. $\mathrm{HCl}(10 \%, 40 \mathrm{~mL})$, and heat at reflux for $4 \mathrm{~h}$. Removal of solvents in vacuo afforded 18 as a yellow solid (1.35 g, 66\% yield over two steps).

\subsubsection{Kynuramine Dihydrobromide (20)}

A solution of kynuramine methyl carbamate 18 (1.346 g, $6.06 \mathrm{mmol})$ in $\mathrm{HBr}$ saturated $\mathrm{AcOH}$ $\left(20 \mathrm{~mL}\right.$ ) was heated to $80{ }^{\circ} \mathrm{C}$ and stirred for $18 \mathrm{~h}$ under $\mathrm{N}_{2}$. The brown solution was cooled to room temperature and THF $(80 \mathrm{~mL})$ was added which resulted in the formation of a precipitate. The mixture was stirred in an ice bath for $20 \mathrm{~min}$, then filtered. The brown solid was dried under $\mathrm{N}_{2}$ to afford $\mathbf{2 0}$ (1.89 g, 96\% yield).

Mp 192.0-193.0 ${ }^{\circ} \mathrm{C}$ (lit. [21] 214.0-216.0 ${ }^{\circ} \mathrm{C}$ ); IR $v_{\max }$ (ATR) 3400, 1705, 1619, 1543, $1261 \mathrm{~cm}^{-1}$; ${ }^{1} \mathrm{H}$ NMR $\left(\mathrm{CD}_{3} \mathrm{OD}, 400 \mathrm{MHz}\right) \delta_{\mathrm{H}} 8.14(1 \mathrm{H}, \mathrm{dd}, J=7.8,1.4 \mathrm{~Hz}, \mathrm{H}-6), 7.69(1 \mathrm{H}, \mathrm{td}, J=7.9,1.4 \mathrm{~Hz}$, H-4), $7.51(1 \mathrm{H}, \mathrm{td}, J=7.8,1.1 \mathrm{~Hz}, \mathrm{H}-5), 7.42(1 \mathrm{H}, \mathrm{dd}, J=7.9,1.1 \mathrm{~Hz}, \mathrm{H}-3), 3.55(2 \mathrm{H}, \mathrm{t}, J=6.4 \mathrm{~Hz}$, $\left.\mathrm{H}_{2}-9\right), 3.34\left(2 \mathrm{H}, \mathrm{t}, J=6.4 \mathrm{~Hz}, \mathrm{H}_{2}-10\right)$; ${ }^{13} \mathrm{C} \mathrm{NMR}\left(\mathrm{CD}_{3} \mathrm{OD}, 100 \mathrm{MHz}\right) \delta_{\mathrm{C}} 200.8(\mathrm{C}-8), 162.8(\mathrm{C}-2)$, 136.3 (C-4), 132.8 (C-6), 128.9 (C-5), 128.5 (C-7), 125.4 (C-3), 37.8 (C-9), 35.9 (C-10); (+)-ESIMS $m / z 165[\mathrm{M}+\mathrm{H}]^{+} ;(+)$-HRESIMS $[\mathrm{M}+\mathrm{H}]^{+} 165.1016$ (calcd. for $\left.\mathrm{C}_{9} \mathrm{H}_{13} \mathrm{~N}_{2} \mathrm{O}, 165.1022\right)$.

\subsection{4. $N$-(3,4-Dimethoxyphenethyl)acetamide (22)}

$\mathrm{Et}_{3} \mathrm{~N}(1.54 \mathrm{~mL}, 0.01 \mathrm{~mol})$ and acetic anhydride $(1.56 \mathrm{~mL}, 0.02 \mathrm{~mol})$ was added to 2-(3,4-dimethoxyphenyl)ethylamine $(\mathbf{2 1})(0.93 \mathrm{~mL}, 5.52 \mathrm{mmol})$. The reaction mixture was yellow, and was stirred at room temperature for $1 \mathrm{~h}$ under $\mathrm{N}_{2} . \mathrm{CH}_{2} \mathrm{Cl}_{2}(100 \mathrm{~mL})$ was added then washed with $\mathrm{H}_{2} \mathrm{O}$ $(50 \mathrm{~mL})$ and the organic phase dried in vacuo, to afford 22 as a yellow solid (1.17 g, 95\% yield).

Mp 97.8-98.6 ${ }^{\circ} \mathrm{C}$ (lit. [22] 100.0-101.0 $\left.{ }^{\circ} \mathrm{C}\right) ; R_{\mathrm{f}}\left(5 \% \mathrm{MeOH} / \mathrm{CH}_{2} \mathrm{Cl}_{2}\right)$ 0.39; IR $v_{\max }$ (ATR) 3250, 3080, 2928, 2840, 1631, 1590, 1516, 1261, 1232, 1155, $1019 \mathrm{~cm}^{-1} ;{ }^{1} \mathrm{H} \mathrm{NMR}\left(\mathrm{CDCl}_{3}, 400 \mathrm{MHz}\right)$ $\delta_{\mathrm{H}} 6.80(1 \mathrm{H}, \mathrm{d}, J=8.0 \mathrm{~Hz}, \mathrm{H}-8), 6.72(1 \mathrm{H}, \mathrm{d}, J=1.8 \mathrm{~Hz}, \mathrm{H}-5), 6.70(1 \mathrm{H}, \mathrm{dd}, J=8.0,1.8 \mathrm{~Hz}, \mathrm{H}-9)$, $5.55\left(1 \mathrm{H}\right.$, br s, NH-1), 3.87 (6H, s, OMe), $3.30\left(2 \mathrm{H}, \mathrm{dt}, J=7.0,7.0 \mathrm{~Hz}, \mathrm{H}_{2}-2\right), 2.60(2 \mathrm{H}, \mathrm{t}, J=7.0 \mathrm{~Hz}$, $\left.\mathrm{H}_{2}-3\right), 1.92\left(3 \mathrm{H}, \mathrm{s}, \mathrm{H}_{3}-11\right) ;{ }^{13} \mathrm{C} \mathrm{NMR}\left(\mathrm{CDCl}_{3}, 100 \mathrm{MHz}\right) \delta_{\mathrm{C}} 170.0$ (C-10), 149.1 (C-6), 147.7 (C-7), 131.3 (C-4), 120.6 (C-9), 111.9 (C-8), 111.4 (C-5), 55.9 (OMe × 2), 40.7 (C-2), 35.2 (C-3), 23.3 (C-11); (+)-ESIMS m/z $224[\mathrm{M}+\mathrm{H}]^{+}$; (+)-HRESIMS [M + H] ${ }^{+} 224.1279$ (calcd. for $\mathrm{C}_{12} \mathrm{H}_{18} \mathrm{NO}_{3}$, 224.1281). ${ }^{1} \mathrm{H}$ and ${ }^{13} \mathrm{C}$ NMR data agreed with literature [22].

\subsection{5. $N$-(3,4-Dimethoxyphenethyl)-3-methylbut-2-enamide (23)}

To a solution of 3,3-dimethylacrylic acid $(100 \mathrm{mg}, 1.00 \mathrm{mmol})$ in dry DMF $(3 \mathrm{~mL})$ was added 2-(3,4-dimethoxyphenyl)ethylamine (21) $(0.17 \mathrm{~mL}, 1.00 \mathrm{mmol})$, PyBOP (520 mg, $1.00 \mathrm{mmol})$ and $\mathrm{Et}_{3} \mathrm{~N}(0.42 \mathrm{~mL}, 3.00 \mathrm{mmol})$. The mixture was stirred under $\mathrm{N}_{2}$ at room temperature for $20 \mathrm{~h} . \mathrm{CH}_{2} \mathrm{Cl}_{2}$ 
(20 mL) was added, washed with $\mathrm{H}_{2} \mathrm{O}(30 \mathrm{~mL})$, and the organic phase dried in vacuo. EtOAc $(75 \mathrm{~mL})$ was added and washed with $5 \%$ aq. $\mathrm{K}_{2} \mathrm{CO}_{3}(50 \mathrm{~mL}), 10 \% \mathrm{HCl}(10 \mathrm{~mL})$ and brine $(20 \mathrm{~mL})$. The organic phase was then dried $\left(\mathrm{MgSO}_{4}\right)$ and solvent removed in vacuo to give $\mathbf{2 3}$ as an orange-brown solid (0.24 g, 92\% yield).

$\mathrm{Mp} 67.0-68.2{ }^{\circ} \mathrm{C} ; R_{\mathrm{f}}\left(5 \% \mathrm{MeOH} / \mathrm{CH}_{2} \mathrm{Cl}_{2}\right)$ 0.22; IR $v_{\max }$ (ATR) 3302, 3002, 2939, 1666, 1141, $1027 \mathrm{~cm}^{-1} ;{ }^{1} \mathrm{H} \mathrm{NMR}\left(\mathrm{CDCl}_{3}, 400 \mathrm{MHz}\right) \delta_{\mathrm{H}} 6.79(1 \mathrm{H}, \mathrm{d}, J=8.4 \mathrm{~Hz}, \mathrm{H}-8), 6.73-6.71(2 \mathrm{H}, \mathrm{m}, \mathrm{H}-5$ and $\mathrm{H}-9), 5.48$ (1H, s, H-11), 3.84 (6H, s, OMe), 3.50 (2H, dt, $\left.J=7.2,7.2 \mathrm{~Hz}, \mathrm{H}_{2}-2\right), 2.76(2 \mathrm{H}, \mathrm{t}, J=7.2 \mathrm{~Hz}$,

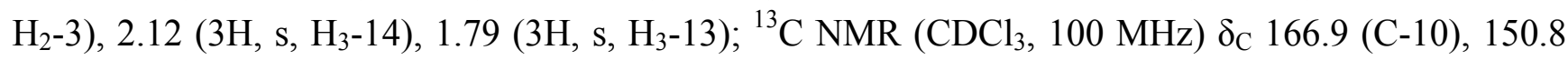
(C-12), 148.9 (C-6), 147.5 (C-7), 131.5 (C-4), 120.6 (C-9), 118.4 (C-11), 111.9 (C-5), 111.3 (C-8), $55.8(\mathrm{OMe} \times 2), 40.3(\mathrm{C}-2), 35.3(\mathrm{C}-3), 27.0(\mathrm{C}-13), 19.7$ (C-14); (+)-ESIMS m/z $264[\mathrm{M}+\mathrm{H}]^{+}$; (+)-HRESIMS $[\mathrm{M}+\mathrm{H}]^{+} 264.1595$ (calcd. for $\mathrm{C}_{15} \mathrm{H}_{22} \mathrm{NO}_{3}, 264.1594$ ).

\subsection{6. $N$-(3,4-Dimethoxyphenethyl)benzamide (24)}

To a cold $\left(0^{\circ} \mathrm{C}\right)$ solution of 2-(3,4-dimethoxyphenyl)ethylamine (21) $(0.093 \mathrm{~mL}, 0.55 \mathrm{mmol})$ and $\mathrm{Et}_{3} \mathrm{~N}(0.35 \mathrm{~mL}, 2.48 \mathrm{mmol})$ in THF $(7.0 \mathrm{~mL})$ was added benzoyl chloride $(0.223 \mathrm{~mL}, 1.93 \mathrm{mmol})$. The milky white solution was warmed to room temperature and solvents were removed in vacuo. $\mathrm{CHCl}_{3}$ $(20 \mathrm{~mL})$ was added, the solution washed with $10 \%$ aq. $\mathrm{NaCO}_{3}(50 \mathrm{~mL}), \mathrm{H}_{2} \mathrm{O}(20 \mathrm{~mL})$ and brine $(20 \mathrm{~mL})$ and then the organic phase was dried in vacuo. The residue was triturated with hexane $(6 \mathrm{~mL})$ and EtOAc ( $2 \mathrm{~mL}$ ) to give 24 as a greenish-white solid ( $90 \mathrm{mg}, 57 \%$ yield).

Mp 85.0-85.8 ${ }^{\circ} \mathrm{C}$ (lit. [23] 85.0-86.0 $\left.{ }^{\circ} \mathrm{C}\right) ; R_{\mathrm{f}}\left(5 \% \mathrm{MeOH} / \mathrm{CH}_{2} \mathrm{Cl}_{2}\right)$ 0.67; IR $v_{\max }$ (ATR) 3236, 2981, 1634, 1590, $1231 \mathrm{~cm}^{-1} ;{ }^{1} \mathrm{H}$ NMR $\left(\mathrm{CDCl}_{3}, 400 \mathrm{MHz}\right) \delta_{\mathrm{H}} 7.71-7.69(2 \mathrm{H}, \mathrm{m}, \mathrm{H}-12$ and $\mathrm{H}-16), 7.44(1 \mathrm{H}$, $\mathrm{tt}, J=6.4,1.2 \mathrm{~Hz}, \mathrm{H}-14), 7.38-7.34(2 \mathrm{H}, \mathrm{m}, \mathrm{H}-13$ and $\mathrm{H}-15), 6.78(1 \mathrm{H}, \mathrm{d}, J=8.0 \mathrm{~Hz}, \mathrm{H}-8)$, 6.74-6.72 (2H, m, H-5 and H-9), 3.82 (3H, s, OMe), 3.79 (3H, s, OMe), $3.66\left(2 \mathrm{H}, \mathrm{t}, J=7.2 \mathrm{~Hz}, \mathrm{H}_{2}-2\right)$, $2.85\left(2 \mathrm{H}, \mathrm{t}, J=7.2 \mathrm{~Hz}, \mathrm{H}_{2}-3\right) ;{ }^{13} \mathrm{C} \mathrm{NMR}\left(\mathrm{CDCl}_{3}, 100 \mathrm{MHz}\right) \delta_{\mathrm{C}} 167.6(\mathrm{C}-10), 148.9$ (C-6), 147.5 (C-7), 134.2 (C-11), 131.4 (C-14), 131.3 (C-4), 128.4 (C-13 and C-15), 126.8 (C-12 and C-16), 120.6 (C-9), 111.9 (C-5), $111.3(\mathrm{C}-8), 55.7$ (OMe × 2), $41.3(\mathrm{C}-2), 35.1(\mathrm{C}-3)$; (+)-ESIMS m/z $286[\mathrm{M}+\mathrm{H}]^{+}$; (+)-HRESIMS $[\mathrm{M}+\mathrm{H}]^{+} 286.1437$ (calcd. for $\mathrm{C}_{17} \mathrm{H}_{20} \mathrm{NO}_{3}, 286.1438$ ). ${ }^{1} \mathrm{H}$ NMR data agreed with literature [23].

\subsection{7. $N$-(3,4-Dimethoxyphenethyl)-2-phenylacetamide (25)}

To a solution of phenylacetic acid $(200 \mathrm{mg}, 1.47 \mathrm{mmol})$ in dry DMF (3 mL) was added 2-(3,4-dimethoxyphenyl)ethylamine (21) $(0.25 \mathrm{~mL}, 1.47 \mathrm{mmol})$, PyBOP (764 mg, $1.47 \mathrm{mmol})$ and $\mathrm{Et}_{3} \mathrm{~N}(0.62 \mathrm{~mL}, 4.41 \mathrm{mmol})$. The mixture was stirred under $\mathrm{N}_{2}$ at room temperature for $26 \mathrm{~h} . \mathrm{CH}_{2} \mathrm{Cl}_{2}$ $(20 \mathrm{~mL})$ was added, washed with $\mathrm{H}_{2} \mathrm{O}(30 \mathrm{~mL})$, and the organic phase dried in vacuo. The crude product was triturated with hexane $(15 \mathrm{~mL})$ and EtOAc $(7 \mathrm{~mL})$ to yield a white solid that was recrystallized from ethanol ( $3 \mathrm{~mL})$ to afford 25 as white crystals $(0.438 \mathrm{~g}, 99 \%$ yield).

Mp 111.1-112.2 ${ }^{\circ} \mathrm{C}$ (lit. [24] 110-111 ${ }^{\circ} \mathrm{C}$ ); $R_{\mathrm{f}}$ (3 EtOAc:1 Hex) 0.40; IR $v_{\max }$ (ATR) 3245, 3008, 2994, 1660, 1605, $1232 \mathrm{~cm}^{-1}$; ${ }^{1} \mathrm{H}$ NMR $\left(\mathrm{CDCl}_{3}, 400 \mathrm{MHz}\right) \delta_{\mathrm{H}} 7.32-7.25(3 \mathrm{H}, \mathrm{m}, \mathrm{H}-14, \mathrm{H}-15$ and $\mathrm{H}-16), 7.16(2 \mathrm{H}, \mathrm{dd}, J=8.0,2.0 \mathrm{~Hz}, \mathrm{H}-13$ and H-17), $6.71(1 \mathrm{H}, \mathrm{d}, J=8.2 \mathrm{~Hz}, \mathrm{H}-8), 6.59(1 \mathrm{H}, \mathrm{d}$, $J=2.0 \mathrm{~Hz}, \mathrm{H}-5), 6.54(1 \mathrm{H}, \mathrm{dd}, J=8.2,2.0 \mathrm{~Hz}, \mathrm{H}-9), 5.36(1 \mathrm{H}, \mathrm{br} \mathrm{s}, \mathrm{NH}-1), 3.85$ (3H, s, OMe), 3.81 
(3H, s, OMe), $3.53\left(2 \mathrm{H}, \mathrm{s}, \mathrm{H}_{2}-11\right), 3.44\left(2 \mathrm{H}, \mathrm{dt}, J=6.9,6.9 \mathrm{~Hz}, \mathrm{H}_{2}-2\right), 2.67\left(2 \mathrm{H}, \mathrm{t}, J=6.9 \mathrm{~Hz}, \mathrm{H}_{2}-3\right)$; ${ }^{13} \mathrm{C} \mathrm{NMR}\left(\mathrm{CDCl}_{3}, 100 \mathrm{MHz}\right) \delta_{\mathrm{C}} 170.9(\mathrm{C}-10), 149.0$ (C-6 or C-7), 147.6 (C-6 or C-7), $134.8(\mathrm{C}-12)$, 131.1 (C-4), 129.4 (C-13 and C-17), 129.0 (C-14 and C-16), 127.3 (C-15), 120.5 (C-9), 111.7 (C-5), 111.3 (C-8), 55.9 (OMe), 55.8 (OMe), 43.9 (C-11), 40.7 (C-2), 35.0 (C-3); (+)-ESIMS m/z 300 $[\mathrm{M}+\mathrm{H}]^{+}$; (+)-HRESIMS $[\mathrm{M}+\mathrm{H}]^{+} 300.1593$ (calcd. for $\mathrm{C}_{18} \mathrm{H}_{22} \mathrm{NO}_{3}, 300.1594$ ). ${ }^{1} \mathrm{H}$ NMR data agreed with literature [24].

\subsection{8. $\mathrm{N}$-(3,4-Dimethoxyphenethyl)-3-phenylpropanamide (26)}

To a cold $\left(0{ }^{\circ} \mathrm{C}\right)$ solution of 2-(3,4-dimethoxyphenyl)ethylamine (21) $(90 \mu \mathrm{L}, 0.55 \mathrm{mmol})$ and $\mathrm{Et}_{3} \mathrm{~N}$ $(0.35 \mathrm{~mL}, 2.48 \mathrm{mmol})$ in THF $(4.5 \mathrm{~mL})$ was added dihydrocinnamoyl chloride $(0.29 \mathrm{~mL}, 1.93 \mathrm{mmol})$. The milky white solution was warmed to room temperature and then the solvents were removed in vacuo. $\mathrm{CHCl}_{3}(20 \mathrm{~mL})$ was added, the solution washed with $10 \%$ aq. $\mathrm{NaCO}_{3}(50 \mathrm{~mL}), \mathrm{H}_{2} \mathrm{O}(20 \mathrm{~mL})$ and brine $(20 \mathrm{~mL})$ and then the organic phase was dried in vacuo. The residue was triturated with hexane $(7 \mathrm{~mL})$ and EtOAc $(2 \mathrm{~mL})$ to give 26 as a pale yellow solid ( $0.16 \mathrm{~g}, 93 \%$ yield $)$.

$\mathrm{Mp} 123.1-124.0^{\circ} \mathrm{C} ; R_{\mathrm{f}}\left(5 \% \mathrm{MeOH} / \mathrm{CH}_{2} \mathrm{Cl}_{2}\right)$ 0.45; IR $v_{\max }$ (ATR) 3249, 2974, 1631, 1534, $1232 \mathrm{~cm}^{-1}$; ${ }^{1} \mathrm{H}$ NMR $\left(\mathrm{CDCl}_{3}, 400 \mathrm{MHz}\right) \delta_{\mathrm{H}} 7.29-7.26$ (2H, m, H-15, H-17), 7.24-7.16 (3H, m, H-14, H-16, H-18), $6.77(1 \mathrm{H}, \mathrm{d}, J=8.0 \mathrm{~Hz}, \mathrm{H}-8), 6.65(1 \mathrm{H}, \mathrm{d}, J=2.0 \mathrm{~Hz}, \mathrm{H}-5), 6.61(1 \mathrm{H}, \mathrm{dd}, J=8.0,2.0 \mathrm{~Hz}, \mathrm{H}-9), 3.85$ $(3 \mathrm{H}, \mathrm{s}, \mathrm{OMe}), 3.84(3 \mathrm{H}, \mathrm{s}, \mathrm{OMe}), 3.45\left(2 \mathrm{H}, \mathrm{dt}, J=7.2,7.2 \mathrm{~Hz}, \mathrm{H}_{2}-2\right), 2.94(2 \mathrm{H}, \mathrm{t}, J=8.0 \mathrm{~Hz}$, $\left.\mathrm{H}_{2}-12\right), 2.68\left(2 \mathrm{H}, \mathrm{t}, J=7.2 \mathrm{~Hz}, \mathrm{H}_{2}-3\right), 2.42\left(2 \mathrm{H}, \mathrm{t}, J=8.0 \mathrm{~Hz}, \mathrm{H}_{2}-11\right) ;{ }^{13} \mathrm{C} \mathrm{NMR}\left(\mathrm{CDCl}_{3}, 100 \mathrm{MHz}\right)$ $\delta_{\mathrm{C}} 172.0(\mathrm{C}-10), 149.0$ (C-6), 147.7 (C-7), 141.0 (C-13), 131.3 (C-4), 128.6 (C-15 and C-17), 128.3 (C-14 and C-18), 126.2 (C-16), 120.6 (C-9), 111.8 (C-5), $111.3(\mathrm{C}-8), 55.9$ (OMe $\times 2), 40.6(\mathrm{C}-2)$, 38.5 (C-11), 35.2 (C-3), $31.7(\mathrm{C}-12)$; (+)-ESIMS m/z $314[\mathrm{M}+\mathrm{H}]^{+}$; (+)-HRESIMS [M + H] 314.1748 (calcd. for $\mathrm{C}_{19} \mathrm{H}_{24} \mathrm{NO}_{3}, 314.1751$ ).

\subsection{9. $N$-(3,4-Dimethoxyphenethyl)palmitamide (27)}

To a cold $\left(0{ }^{\circ} \mathrm{C}\right)$ solution of 2-(3,4-dimethoxyphenyl)ethylamine $(\mathbf{2 1})(0.20 \mathrm{~mL}, 1.10 \mathrm{mmol})$ and $\mathrm{Et}_{3} \mathrm{~N}(0.70 \mathrm{~mL}, 5.0 \mathrm{mmol})$ in THF $(10 \mathrm{~mL})$ was added palmitoyl chloride $(1.18 \mathrm{~mL}, 3.86 \mathrm{mmol})$. The milky white solution was warmed to room temperature and then the solvents were removed in vacuo. $\mathrm{CHCl}_{3}(20 \mathrm{~mL})$ was added, the solution washed with $10 \%$ aq. $\mathrm{NaCO}_{3}(50 \mathrm{~mL}), \mathrm{H}_{2} \mathrm{O}(20 \mathrm{~mL})$ and brine $(20 \mathrm{~mL})$ and then the organic phase was dried in vacuo. The residue was triturated with hexane $(10 \mathrm{~mL})$ and EtOAc $(5 \mathrm{~mL})$ to give 27 as a white solid $(0.30 \mathrm{~g}, 65 \%$ yield $)$.

Mp 94.0-95.1 ${ }^{\circ} \mathrm{C} ; R_{\mathrm{f}}\left(3\right.$ EtOAc:1 Hex) 0.73; IR $v_{\max }$ (ATR) 3301, 2955, 2918, 1705, 1638, 1591, $1232,1140 \mathrm{~cm}^{-1} ;{ }^{1} \mathrm{H}$ NMR $\left(\mathrm{CDCl}_{3}, 400 \mathrm{MHz}\right) \delta_{\mathrm{H}} 6.80(1 \mathrm{H}, \mathrm{d}, J=8.4 \mathrm{~Hz}, \mathrm{H}-8), 6.73-6.71(2 \mathrm{H}, \mathrm{m}, \mathrm{H}-5$ and $\mathrm{H}-9), 5.43(1 \mathrm{H}, \mathrm{s}, \mathrm{NH}-1), 3.86(6 \mathrm{H}, \mathrm{s}, \mathrm{OMe}), 3.49\left(2 \mathrm{H}, \mathrm{dt}, J=7.2,7.2 \mathrm{~Hz}, \mathrm{H}_{2}-2\right), 2.75(2 \mathrm{H}, \mathrm{t}$, $\left.J=7.2 \mathrm{~Hz}, \mathrm{H}_{2}-3\right), 2.11\left(2 \mathrm{H}, \mathrm{t}, J=7.6 \mathrm{~Hz}, \mathrm{H}_{2}-11\right), 1.58\left(2 \mathrm{H}\right.$, br t, $\left.J=7.2 \mathrm{~Hz}, \mathrm{H}_{2}-12\right), 1.24(24 \mathrm{H}$, br s, $\left.\mathrm{H}_{2}-13-\mathrm{H}_{2}-24\right), 0.87\left(3 \mathrm{H}, \mathrm{t}, J=7.2 \mathrm{~Hz}, \mathrm{H}_{3}-25\right) ;{ }^{13} \mathrm{C} \mathrm{NMR}\left(\mathrm{CDCl}_{3}, 100 \mathrm{MHz}\right) \delta_{\mathrm{C}} 173.2(\mathrm{C}-10), 149.2$ (C-6), 147.8 (C-7), 131.6 (C-4), 120.8 (C-9), 112.0 (C-5), 111.4 (C-8), 56.0 (OMe × 2), 40.7 (C-2), 37.0 (C-11), 35.5 (C-3), 32.1 (C-23), 29.8 (C-13-C-22), 25.9 (C-12), 22.8 (C-24), 14.3 (C-25); $(+)$-ESIMS $m / z 420[\mathrm{M}+\mathrm{H}]^{+}$; (+)-HRESIMS [M + H] 420.3460 (calcd. for $\mathrm{C}_{26} \mathrm{H}_{45} \mathrm{NO}_{3}, 420.3472$ ). 
3.2.10. General Procedure for the Preparation of $N$-Acyl Dopamine Analogues 28-33

To a stirred solution of 3,4-dimethoxyphenethylamide $\mathbf{2 8}-\mathbf{3 3}$ in dry $\mathrm{CH}_{2} \mathrm{Cl}_{2}(20 \mathrm{~mL})$ in a salted ice bath, boron tribromide (10 equiv.) in dry $\mathrm{CH}_{2} \mathrm{Cl}_{2}(10 \mathrm{~mL})$ was added dropwise. The solution turned from yellow to orange, and was stirred under $\mathrm{N}_{2}$ for $20 \mathrm{~h}$ with temperature rising to room temperature. $\mathrm{MeOH}(3 \mathrm{~mL})$ and saturated brine $(5 \mathrm{~mL})$ were then added dropwise. EtOAc $(30 \mathrm{~mL})$ was added, the organic phase washed with $\mathrm{H}_{2} \mathrm{O}(30 \mathrm{~mL})$, dried $\left(\mathrm{MgSO}_{4}\right)$ and solvent removed in vacuo to afford the $\mathrm{N}$-acyl dopamine analogue. The product was used in the subsequent reaction without further purification.

\subsubsection{1. $N$-Acetyl Dopamine (28)}

From $N$-(3,4-dimethoxyphenethyl)acetamide (22) $(200 \mathrm{mg}, 0.9 \mathrm{mmol})$ to afford $\mathbf{2 8}$ as a yellow oil (158 mg, 90\% yield).

IR $v_{\max }$ (ATR) 3215, 1624, 1558, 1439, $1284 \mathrm{~cm}^{-1} ;{ }^{1} \mathrm{H}$ NMR $\left(\mathrm{CD}_{3} \mathrm{OD}, 400 \mathrm{MHz}\right) \delta_{\mathrm{H}} 6.69(1 \mathrm{H}, \mathrm{d}$, $J=8.0 \mathrm{~Hz}, \mathrm{H}-8), 6.65(1 \mathrm{H}, \mathrm{d}, J=2.0 \mathrm{~Hz}, \mathrm{H}-5), 6.45(1 \mathrm{H}, \mathrm{dd}, J=8.0,2.0 \mathrm{~Hz}, \mathrm{H}-9), 3.30(2 \mathrm{H}, \mathrm{t}$, $\left.J=7.2 \mathrm{~Hz}, \mathrm{H}_{2}-2\right), 2.60\left(2 \mathrm{H}, \mathrm{t}, J=7.2 \mathrm{~Hz}, \mathrm{H}_{2}-3\right), 1.89\left(3 \mathrm{H}, \mathrm{s}, \mathrm{H}_{3}-11\right) ;{ }^{13} \mathrm{C} \mathrm{NMR}\left(\mathrm{CD}_{3} \mathrm{OD}, 100 \mathrm{MHz}\right)$ $\delta_{\mathrm{C}} 172.1(\mathrm{C}-10), 144.8$ (C-6), 143.3 (C-7), 130.7 (C-4), 119.8 (C-9), 115.6 (C-8), 115.1 (C-5), 41.0 (C-2), 34.4 (C-3), 21.2 (C-11); (+)-ESIMS m/z $196[\mathrm{M}+\mathrm{H}]^{+} ;(+)$-HRESIMS [M + H] 196.0970 (calcd. for $\mathrm{C}_{10} \mathrm{H}_{14} \mathrm{NO}_{3}, 196.0968$ ).

3.2.10.2. $N$-(3,4-Dihydroxyphenethyl)-3-methylbut-2-enamide (29)

From $N$-(3,4-dimethoxyphenethyl)-3-methylbut-2-enamide (23) (90 mg, $0.35 \mathrm{mmol})$ to afford 29 as a yellow oil ( $81 \mathrm{mg}, 98 \%$ yield).

IR $v_{\max }$ (ATR) 3240, 2976, 1657, 1598, 1442, $1165 \mathrm{~cm}^{-1} ;{ }^{1} \mathrm{H}$ NMR $\left(\mathrm{CD}_{3} \mathrm{OD}, 400 \mathrm{MHz}\right) \delta_{\mathrm{H}} 6.77$ $(1 \mathrm{H}, \mathrm{d}, J=8.0 \mathrm{~Hz}, \mathrm{H}-8), 6.65(1 \mathrm{H}, \mathrm{d}, J=2.0 \mathrm{~Hz}, \mathrm{H}-5), 6.51(1 \mathrm{H}, \mathrm{dd}, J=8.0,2.0 \mathrm{~Hz}, \mathrm{H}-9), 5.50(1 \mathrm{H}, \mathrm{s}$, $\mathrm{H}-11), 3.30\left(2 \mathrm{H}, \mathrm{t}, J=8.0 \mathrm{~Hz}, \mathrm{H}_{2}-2\right), 2.62\left(2 \mathrm{H}, \mathrm{t}, J=8.0 \mathrm{~Hz}, \mathrm{H}_{2}-3\right), 2.06\left(3 \mathrm{H}, \mathrm{s}, \mathrm{H}_{3}-14\right), 1.80(3 \mathrm{H}, \mathrm{s}$, $\left.\mathrm{H}_{3}-13\right) ;{ }^{13} \mathrm{C}$ NMR $\left(\mathrm{CD}_{3} \mathrm{OD}, 100 \mathrm{MHz}\right) \delta_{\mathrm{C}} 169.7$ (C-10), 151.4 (C-12), 146.2 (C-6), 144.7 (C-7), 132.2 (C-4), 121.0 (C-9), 119.6 (C-11), 116.9 (C-5), 116.3 (C-8), 42.1 (C-2), 36.1 (C-3), 27.2 (C-13), 20.0 (C-14); (+)-ESIMS m/z $236[\mathrm{M}+\mathrm{H}]^{+}$; (+)-HRESIMS [M + H] 236.1275 (calcd. for $\left.\mathrm{C}_{13} \mathrm{H}_{18} \mathrm{NO}_{3}, 236.1281\right)$.

\subsubsection{3. $N$-(3,4-Dihydroxyphenethyl)benzamide (30)}

From $N$-(3,4-dimethoxyphenethyl)benzamide (24) $(196 \mathrm{mg}, 0.69 \mathrm{mmol})$ to afford 30 as a yellow oil (150 mg, 85\% yield).

IR $v_{\max }$ (ATR) 3251, 2257, 1634, 1529, $1285 \mathrm{~cm}^{-1} ;{ }^{1} \mathrm{H}$ NMR (DMSO- $\left.d_{6}, 400 \mathrm{MHz}\right) \delta_{\mathrm{H}} 8.49(1 \mathrm{H}, \mathrm{t}$, $J=5.6 \mathrm{~Hz}, \mathrm{NH}-1), 7.83-7.80(2 \mathrm{H}, \mathrm{m}, \mathrm{H}-12$ and H-16), $7.51(1 \mathrm{H}, \mathrm{tt}, J=7.2,1.6 \mathrm{~Hz}, \mathrm{H}-14), 7.45(2 \mathrm{H}$, $\mathrm{td}, J=6.8,1.6 \mathrm{~Hz}, \mathrm{H}-13$ and H-15), 6.65-6.62 (2H, m, H-5 and H-8), $6.47(1 \mathrm{H}, \mathrm{dd}, J=8.0,2.0 \mathrm{~Hz}$, $\mathrm{H}-9), 3.39\left(2 \mathrm{H}, \mathrm{dt}, J=8.0,5.6 \mathrm{~Hz}, \mathrm{H}_{2}-2\right), 2.65\left(2 \mathrm{H}, \mathrm{t}, J=8.0 \mathrm{~Hz}, \mathrm{H}_{2}-3\right) ;{ }^{13} \mathrm{C}$ NMR (DMSO- $d_{6}$, $100 \mathrm{MHz}) \delta_{\mathrm{C}} 166.0(\mathrm{C}-10), 145.0$ (C-6), 143.4 (C-7), 134.6 (C-11), 130.9 (C-14), 130.2 (C-4), 128.2 (C-12 and C-16), 127.0 (C-13 and C-15), 119.2 (C-9), 115.9 (C-5), 115.4 (C-8), 41.2 (C-2), 34.6 (C-3); (+)-ESIMS $m / z 258[\mathrm{M}+\mathrm{H}]^{+} ;(+)$-HRESIMS $[\mathrm{M}+\mathrm{H}]^{+} 258.112$ (calcd. for $\mathrm{C}_{15} \mathrm{H}_{16} \mathrm{NO}_{3}, 258.1125$ ). 
3.2.10.4. $N$-(3,4-Dihydroxyphenethyl)-2-phenylacetamide (31)

From $N$-(3,4-dimethoxyphenethyl)-2-phenylacetamide (25) $(200 \mathrm{mg}, 0.67 \mathrm{mmol})$ to afford 31 as a yellow oil (142 mg, 79\% yield).

IR $v_{\max }$ (ATR) 3546, 3399, 3236, 1636, 1613, 1524, 1495, 1358, 1282, $1193 \mathrm{~cm}^{-1} ;{ }^{1} \mathrm{H}$ NMR $\left(\mathrm{CD}_{3} \mathrm{OD}, 400 \mathrm{MHz}\right) \delta_{\mathrm{H}} 7.31-7.26(2 \mathrm{H}, \mathrm{m}, \mathrm{H}-14, \mathrm{H}-16), 7.24-7.30(3 \mathrm{H}, \mathrm{m}, \mathrm{H}-13, \mathrm{H}-15$ and H-17), $6.65(1 \mathrm{H}, \mathrm{d}, J=8.0 \mathrm{~Hz}, \mathrm{H}-8), 6.62(1 \mathrm{H}, \mathrm{d}, J=2.0 \mathrm{~Hz}, \mathrm{H}-5), 6.45(1 \mathrm{H}, \mathrm{dd}, J=8.0,2.0 \mathrm{~Hz}, \mathrm{H}-9), 3.46$ $\left(2 \mathrm{H}, \mathrm{s}, \mathrm{H}_{2}-11\right), 3.36-3.33\left(2 \mathrm{H}, \mathrm{m}, \mathrm{H}_{2}-2\right), 2.62\left(2 \mathrm{H}, \mathrm{t}, J=7.2 \mathrm{~Hz}, \mathrm{H}_{2}-3\right) ;{ }^{13} \mathrm{C}$ NMR $\left(\mathrm{CD}_{3} \mathrm{OD}, 100 \mathrm{MHz}\right)$ $\delta_{\mathrm{C}} 174.1(\mathrm{C}-10), 146.2$ (C-6), 144.8 (C-7), 136.5 (C-12), 131.9 (C-4), 130.1 (C-13 and C-17), 129.6 (C-14 and C-16), 127.9 (C-15), 121.2 (C-9), 116.7 (C-5), 116.4 (C-8), 43.9 (C-11), 42.4 (C-2), 35.8 (C-3); (+)-ESIMS m/z $272[\mathrm{M}+\mathrm{H}]^{+}$; (+)-HRESIMS [M + H] 272.1272 (calcd. for $\mathrm{C}_{16} \mathrm{H}_{18} \mathrm{NO}_{3}$, 272.1281). ${ }^{1} \mathrm{H}$ NMR data agreed with literature [25].

\subsubsection{5. $\mathrm{N}$-(3,4-Dihydroxyphenethyl)-3-phenylpropanamide (32)}

From $N$-(3,4-dimethoxyphenethyl)-3-phenylpropanamide (26) (298 mg, $0.95 \mathrm{mmol})$ to afford 32 as a yellow oil (240 $\mathrm{mg}, 89 \%$ yield).

IR $v_{\max }$ (ATR) 3214, 1604, 1521, 1446, 1281, $1190 \mathrm{~cm}^{-1} ;{ }^{1} \mathrm{H}$ NMR $\left(\mathrm{CD}_{3} \mathrm{OD}, 400 \mathrm{MHz}\right) \delta_{\mathrm{H}} 7.15$ $(2 \mathrm{H}, \mathrm{dt}, J=8.4,0.8 \mathrm{~Hz}, \mathrm{H}-15, \mathrm{H}-17), 7.08-7.06(3 \mathrm{H}, \mathrm{m}, \mathrm{H}-14, \mathrm{H}-16$ and H-18), $6.60(1 \mathrm{H}, \mathrm{d}, J=8.0 \mathrm{~Hz}$, $\mathrm{H}-8), 6.56(1 \mathrm{H}, \mathrm{d}, J=2.4 \mathrm{~Hz}, \mathrm{H}-5), 6.37(1 \mathrm{H}, \mathrm{dd}, J=8.0,2.4 \mathrm{~Hz}, \mathrm{H}-9), 3.22-3.20\left(2 \mathrm{H}, \mathrm{m}, \mathrm{H}_{2}-2\right), 2.78$ $\left(2 \mathrm{H}, \mathrm{t}, J=8.2 \mathrm{~Hz}, \mathrm{H}_{2}-12\right), 2.48\left(2 \mathrm{H}, \mathrm{t}, J=7.6 \mathrm{~Hz}, \mathrm{H}_{2}-3\right), 2.39\left(2 \mathrm{H}, \mathrm{t}, J=8.2 \mathrm{~Hz}, \mathrm{H}_{2}-11\right)$; ${ }^{13} \mathrm{C} \mathrm{NMR}\left(\mathrm{CDCl}_{3}, 100 \mathrm{MHz}\right) \delta_{\mathrm{C}} 175.6$ (C-10), 146.1 (C-6), 144.6 (C-7), 141.8 (C-13), 131.9 (C-4), 129.5 (C-14, C-15, C-17, and C-18), 127.3 (C-16), 121.1 (C-9), 116.8 (C-5), 116.4 (C-8), 42.5 (C-2), 38.7 (C-11), 35.7 (C-3), 33.0 (C-12); (+)-ESIMS m/z 286 [M+H] ; (+)-HRESIMS [M+H] 286.1433 (calcd. for $\left.\mathrm{C}_{17} \mathrm{H}_{20} \mathrm{NO}_{3}, 286.1438\right) .{ }^{1} \mathrm{H}$ NMR data agreed with literature [25].

\subsubsection{6. $N$-(3,4-Dihydroxyphenethyl)palmitamide (33)}

From $\mathrm{N}$-(3,4-dimethoxyphenethyl)palmitamide (27) (200 $\mathrm{mg}, 0.48 \mathrm{mmol})$ to afford $\mathbf{3 3}$ as a colourless oil (150 mg, 75\% yield).

IR $v_{\max }$ (ATR) 3546, 3401, 3237, 2918, 2059, 1637, 1554, 1356, 1194, $1119 \mathrm{~cm}^{-1} ;{ }^{1} \mathrm{H}$ NMR (DMSO- $\left.d_{6}, 400 \mathrm{MHz}\right) \delta_{\mathrm{H}} 7.78(1 \mathrm{H}, \mathrm{t}, J=5.6 \mathrm{~Hz}, \mathrm{NH}-1), 6.61(1 \mathrm{H}, \mathrm{d}, J=8.0 \mathrm{~Hz}, \mathrm{H}-8), 6.55(1 \mathrm{H}, \mathrm{d}$, $J=2.5 \mathrm{~Hz}, \mathrm{H}-5), 6.41(1 \mathrm{H}, \mathrm{dd}, J=8.0,2.5 \mathrm{~Hz}, \mathrm{H}-9), 3.14\left(2 \mathrm{H}, \mathrm{dt}, J=7.2,5.6 \mathrm{~Hz}, \mathrm{H}_{2}-2\right), 2.50(2 \mathrm{H}, \mathrm{t}$, $\left.J=7.2 \mathrm{~Hz}, \mathrm{H}_{2}-3\right), 2.01\left(2 \mathrm{H}, \mathrm{t}, J=7.6 \mathrm{~Hz}, \mathrm{H}_{2}-11\right), 1.45\left(2 \mathrm{H}, \mathrm{t}, J=6.8 \mathrm{~Hz}, \mathrm{H}_{2}-12\right), 1.23(24 \mathrm{H}$, br s, $\left.\mathrm{H}_{2}-13-\mathrm{H}_{2}-24\right), 0.87\left(3 \mathrm{H}, \mathrm{t}, J=7.2 \mathrm{~Hz}, \mathrm{H}_{3}-25\right) ;{ }^{13} \mathrm{C}$ NMR (DMSO- $\left.d_{6}, 100 \mathrm{MHz}\right) \delta_{\mathrm{C}} 171.8(\mathrm{C}-10), 144.9$ (C-6), 143.4 (C-7), 130.2 (C-4), 119.1 (C-9), 115.8 (C-5), 115.3 (C-8), 40.4 (C-2), 35.4 (C-11), 34.7 (C-3), 31.2 (C-23), 28.7 (C-13-C-22), 25.2 (C-12), 22.0 (C-24), 13.9 (C-25); (+)-ESIMS m/z 391 $[\mathrm{M}+\mathrm{H}]^{+}$; (+)-HRESIMS $[\mathrm{M}+\mathrm{H}]^{+} 392.3156$ (calcd. for $\mathrm{C}_{24} \mathrm{H}_{42} \mathrm{NO}_{3}, 392.3159$ ). ${ }^{1} \mathrm{H}$ NMR data agreed with literature [26]. 
3.2.11. General Procedure for the Preparation of $N$-Acyl Styelsamine Analogues 13, 34-38

To a solution of $N$-acyl dopamine (1 equiv.) in degassed 2:1 $\mathrm{MeOH}: \mathrm{AcOH}(6 \mathrm{~mL})$ was added kynuramine dihydrobromide (1.05 equiv.) followed by $\mathrm{CeCl}_{3} \cdot 7 \mathrm{H}_{2} \mathrm{O}(0.2$ equiv.). To the stirred yellow solution under $\mathrm{N}_{2}$ was added $\mathrm{Ag}_{2} \mathrm{O}$ (2-4 equiv.) and the suspension warmed to $40{ }^{\circ} \mathrm{C}$ for $1.5 \mathrm{~h}$. The yellow solution was filtered and added dropwise to stirring $\mathrm{HCl}(6 \mathrm{~N}, 15 \mathrm{~mL})$ at $90{ }^{\circ} \mathrm{C}$ and heated for a further 30 min during which time the colour of the solution changed to purple. The solution was dried in vacuo and the residue purified by either RP-2 or RP-18 column chromatography using $\mathrm{H}_{2} \mathrm{O}$ $(0.05 \%$ TFA $)-\mathrm{MeOH}$ solvent mixtures to afford the product as a purple oil.

\subsubsection{Styelsamine B Trifluoroacetate (13)}

Using the general procedure, reaction of $N$-acetyl dopamine (28) (52 $\mathrm{mg}, 0.27 \mathrm{mmol}$ ) with kynuramine dihydrobromide (92 mg, $0.28 \mathrm{mmol}), \mathrm{CeCl}_{3} .7 \mathrm{H}_{2} \mathrm{O}(14.0 \mathrm{mg}, 0.04 \mathrm{mmol})$ and $\mathrm{Ag}_{2} \mathrm{O}$ (123 mg, $0.53 \mathrm{mmol}$ ) afforded, after RP-2 column chromatography, 13 as a purple oil (22.0 mg, $19 \%$ yield).

IR $v_{\max }$ (ATR) 3389, 3075, 1679, 1205, $1138 \mathrm{~cm}^{-1} ; R_{\mathrm{t}}=5.99 \mathrm{~min} ;{ }^{1} \mathrm{H}$ NMR $\left(\mathrm{CD}_{3} \mathrm{OD}, 400 \mathrm{MHz}\right)$ $\delta_{\mathrm{H}} 7.93(1 \mathrm{H}, \mathrm{d}, J=5.8 \mathrm{~Hz}, \mathrm{H}-2), 7.81(1 \mathrm{H}, \mathrm{d}, J=7.8 \mathrm{~Hz}, \mathrm{H}-4), 7.52(1 \mathrm{H}, \mathrm{t}, J=8.0 \mathrm{~Hz}, \mathrm{H}-6), 7.46(1 \mathrm{H}$, $\mathrm{d}, J=8.0 \mathrm{~Hz}, \mathrm{H}-7), 7.20(1 \mathrm{H}, \mathrm{s}, \mathrm{H}-10), 7.14(1 \mathrm{H}, \mathrm{d}, J=5.8 \mathrm{~Hz}, \mathrm{H}-3), 7.10(1 \mathrm{H}, \mathrm{t}, J=7.8 \mathrm{~Hz}, \mathrm{H}-5)$, $3.20\left(2 \mathrm{H}, \mathrm{t}, J=6.8 \mathrm{~Hz}, \mathrm{H}_{2}-13\right), 2.79\left(2 \mathrm{H}, \mathrm{t}, J=6.8 \mathrm{~Hz}, \mathrm{H}_{2}-12\right), 2.04\left(3 \mathrm{H}, \mathrm{s}, \mathrm{H}_{3}-16\right)$; ${ }^{13} \mathrm{C} \mathrm{NMR}$ $\left(\mathrm{CD}_{3} \mathrm{OD}, 100 \mathrm{MHz}\right) \delta_{\mathrm{C}} 174.7(\mathrm{C}-15), 150.8(\mathrm{C}-3 \mathrm{a}), 143.4(\mathrm{C}-2), 142.3$ (C-7a), $138.0(\mathrm{C}-11), 136.2(\mathrm{C}-6)$, 129.7 (C-8a), 127.2 (C-11a), 126.0 (C-4), 123.9 (C-5), 122.6 (C-10), 121.6 (C-11b), 118.9 (C-7), 117.3 (C-9), 115.2 (C-3b), 105.6 (C-3), 39.3 (C-13), 31.9 (C-12), 22.5 (C-16); (+)-ESIMS m/z 320 [M + H] ; (+)-HRESIMS $[\mathrm{M}+\mathrm{H}]^{+} 320.1391$ (calcd. for $\mathrm{C}_{19} \mathrm{H}_{18} \mathrm{~N}_{3} \mathrm{O}_{2}, 320.1394$ ). ${ }^{1} \mathrm{H}$ and ${ }^{13} \mathrm{C} \mathrm{NMR}$ data agreed with literature [6].

\subsubsection{Styelsamine- $N^{14}-3$-methyl-but-2-enamide (34)}

Using the general procedure, reaction of $N$-(3,4-dihydroxyphenethyl)-3-methylbut-2-enamide (29) (98 mg, $0.42 \mathrm{mmol}$ ) with kynuramine dihydrobromide (142 mg, $0.44 \mathrm{mmol}), \mathrm{CeCl}_{3} \cdot 7 \mathrm{H}_{2} \mathrm{O}(22 \mathrm{mg}$, $0.06 \mathrm{mmol})$ and $\mathrm{Ag}_{2} \mathrm{O}(360 \mathrm{mg}, 1.57 \mathrm{mmol})$ afforded, after RP-2 column chromatography, 34 as a purple oil (12.0 mg, 6\% yield).

IR $v_{\max }$ (ATR) 3374, 3069, 1699, 1684, 1499, $1205 \mathrm{~cm}^{-1} ; R_{\mathrm{t}}=9.53 \mathrm{~min} ;{ }^{1} \mathrm{H} \mathrm{NMR}\left(\mathrm{CD}_{3} \mathrm{OD}\right.$, $400 \mathrm{MHz}) \delta_{\mathrm{H}} 7.89(1 \mathrm{H}, \mathrm{d}, J=5.8 \mathrm{~Hz}, \mathrm{H}-2), 7.78(1 \mathrm{H}, \mathrm{d}, J=8.0 \mathrm{~Hz}, \mathrm{H}-4), 7.47$ (2H, br s, H-6 and H-7), $7.14(1 \mathrm{H}, \mathrm{s}, \mathrm{H}-10), 7.11-7.05(2 \mathrm{H}, \mathrm{m}, \mathrm{H}-3$ and H-5), $5.68(1 \mathrm{H}, \mathrm{s}, \mathrm{H}-16), 3.15(2 \mathrm{H}, \mathrm{t}, J=8.4 \mathrm{~Hz}$, $\left.\mathrm{H}_{2}-13\right), 2.75\left(2 \mathrm{H}, \mathrm{t}, J=7.2 \mathrm{~Hz}, \mathrm{H}_{2}-12\right), 2.22\left(3 \mathrm{H}, \mathrm{s}, \mathrm{H}_{3}-19\right), 1.87\left(3 \mathrm{H}, \mathrm{s}, \mathrm{H}_{3}-18\right) ;{ }^{13} \mathrm{C} \mathrm{NMR}\left(\mathrm{CD}_{3} \mathrm{OD}\right.$, $100 \mathrm{MHz}) \delta_{\mathrm{C}} 170.9(\mathrm{C}-15), 153.4(\mathrm{C}-17), 151.0(\mathrm{C}-3 \mathrm{a}), 143.3$ (C-2), $142.5(\mathrm{C}-7 \mathrm{a}), 137.9$ (C-11), 136.1 (C-6), 130.6 (C-8a), 127.0 (C-11a), 126.0 (C-4), 123.8 (C-5), 122.7 (C-11b and C-10), 118.9 (C-16), 118.8 (C-7), 117.5 (C-9), 115.4 (C-3b), 105.4 (C-3), 39.2 (C-13), 32.5 (C-12), 27.5 (C-18), 20.3 (C-19); $(+)$-ESIMS $m / z 360[\mathrm{M}+\mathrm{H}]^{+}$; (+)-HRESIMS $[\mathrm{M}+\mathrm{H}]^{+} 360.1723$ (calcd. for $\mathrm{C}_{22} \mathrm{H}_{22} \mathrm{~N}_{3} \mathrm{O}_{2}, 360.1707$ ). 


\subsubsection{Styelsamine- $N^{14}$-benzamide (35)}

Using the general procedure, reaction of $N$-(3,4-dihydroxyphenethyl)benzamide (30) (43.0 mg, $0.17 \mathrm{mmol}$ ) with kynuramine dihydrobromide (57.0 mg, $0.18 \mathrm{mmol}), \mathrm{CeCl}_{3} \cdot 7 \mathrm{H}_{2} \mathrm{O}(9.0 \mathrm{mg}, 0.03 \mathrm{mmol})$ and $\mathrm{Ag}_{2} \mathrm{O}$ (97 mg, $0.42 \mathrm{mmol}$ ) afforded, after RP-2 column chromatography, 35 as a purple oil (13.0 mg, 15\% yield).

IR $v_{\max }(\mathrm{ATR}) 3327,3052,1654,1582,1205 \mathrm{~cm}^{-1} ; R_{\mathrm{t}}=9.17 \mathrm{~min} ;{ }^{1} \mathrm{H}$ NMR $\left(\mathrm{CD}_{3} \mathrm{OD}, 400 \mathrm{MHz}\right) \delta_{\mathrm{H}}$ $11.66(1 \mathrm{H}, \mathrm{s}, \mathrm{NH}-1), 8.97(1 \mathrm{H}, \mathrm{t}, J=5.4 \mathrm{~Hz}, \mathrm{NH}-14), 8.05(1 \mathrm{H}, \mathrm{d}, J=8.0 \mathrm{~Hz}, \mathrm{H}-2), 8.00(1 \mathrm{H}, \mathrm{d}$, $J=7.8 \mathrm{~Hz}, \mathrm{H}-4), 7.88(2 \mathrm{H}, \mathrm{d}, J=7.6 \mathrm{~Hz}, \mathrm{H}-17$ and H-21), $7.70(1 \mathrm{H}, \mathrm{d}, J=8.0 \mathrm{~Hz}, \mathrm{H}-7), 7.63(1 \mathrm{H}, \mathrm{t}$, $J=8.0 \mathrm{~Hz}, \mathrm{H}-6), 7.56(1 \mathrm{H}, \mathrm{dt}, J=6.4,0.8 \mathrm{~Hz}, \mathrm{H}-19), 7.47(2 \mathrm{H}, \mathrm{t}, J=8.0 \mathrm{~Hz}, \mathrm{H}-18$ and H-20), 7.35-7.31 (2H, m, H-3 and H-10), 7.19 (1H, t, $J=7.8 \mathrm{~Hz}, \mathrm{H}-5), 3.49$ (2H, t, $\left.J=7.6 \mathrm{~Hz}, \mathrm{H}_{2}-13\right), 3.05$ $\left(2 \mathrm{H}, \mathrm{t}, J=7.6 \mathrm{~Hz}, \mathrm{H}_{2}-12\right) ;{ }^{13} \mathrm{C} \mathrm{NMR}\left(\mathrm{CD}_{3} \mathrm{OD}, 100 \mathrm{MHz}\right) \delta_{\mathrm{C}} 171.3(\mathrm{C}-15), 151.4(\mathrm{C}-3 \mathrm{a}), 143.5(\mathrm{C}-2)$, 142.7 (C-7a), 138.1 (C-11), 136.4 (C-6), 134.9 (C-16), 133.1 (C-19), 130.2 (C-11b), 129.7 (C-18 and C-20), 128.4 (C-17 and C-21), 127.6 (C-11a), 126.2 (C-4), 124.0 (C-5), 122.8 (C-10), 122.0 (C-8a), 119.2 (C-7), 117.5 (C-9), 115.5 (C-3b), 105.7 (C-3), 39.9 (C-13), 32.2 (C-12); (+)-ESIMS m/z 382 $[\mathrm{M}+\mathrm{H}]^{+} ;(+)$-HRESIMS $[\mathrm{M}+\mathrm{H}]^{+} 382.1538$ (calcd. for $\mathrm{C}_{24} \mathrm{H}_{20} \mathrm{~N}_{3} \mathrm{O}_{2}, 382.1550$ ).

\subsubsection{Styelsamine- $N^{14}$-2-phenylacetamide (36)}

Using the general procedure, reaction of $N$-(3,4-dihydroxyphenethyl)-2-phenylacetamide (31) (142 mg, $0.52 \mathrm{mmol})$ with kynuramine dihydrobromide $(178 \mathrm{mg}, 0.55 \mathrm{mmol}), \mathrm{CeCl}_{3} \cdot 7 \mathrm{H}_{2} \mathrm{O}(28.0 \mathrm{mg}$, $0.08 \mathrm{mmol})$ and $\mathrm{Ag}_{2} \mathrm{O}(360 \mathrm{mg}, 1.57 \mathrm{mmol})$ afforded, after RP-2 column chromatography, 36 as a purple oil (28.0 mg, $11 \%$ yield).

IR $v_{\max }$ (ATR) 3283, 3068, 1661, $1583 \mathrm{~cm}^{-1} ; R_{\mathrm{t}}=8.25 \mathrm{~min} ;{ }^{1} \mathrm{H}$ NMR $\left(\mathrm{CD}_{3} \mathrm{OD}, 400 \mathrm{MHz}\right) \delta_{\mathrm{H}} 8.05$ $(1 \mathrm{H}, \mathrm{d}, J=6.8 \mathrm{~Hz}, \mathrm{H}-2), 8.00(1 \mathrm{H}, \mathrm{d}, J=8.4 \mathrm{~Hz}, \mathrm{H}-4), 7.62(1 \mathrm{H}, \mathrm{br} \mathrm{d}, J=8.2 \mathrm{~Hz}, \mathrm{H}-6), 7.57$ (1H, d, $J=8.2 \mathrm{~Hz}, \mathrm{H}-7), 7.35-7.33$ (1H, m, H-3), 7.33 (1H, s, H-10), 7.30-7.28 (3H, m, H-5, H-19 and H-21), 7.25-7.17 (3H, m, H-18, H-20 and H-22), $3.56\left(2 \mathrm{H}, \mathrm{s}, \mathrm{H}_{2}-16\right), 3.35$ (2H, t, $\left.J=8.0 \mathrm{~Hz}, \mathrm{H}_{2}-13\right), 2.94$ $\left(2 \mathrm{H}, \mathrm{t}, J=7.6 \mathrm{~Hz}, \mathrm{H}_{2}-12\right) ;{ }^{13} \mathrm{C}$ NMR $\left(\mathrm{CD}_{3} \mathrm{OD}, 100 \mathrm{MHz}\right) \delta_{\mathrm{C}} 175.4(\mathrm{C}-15), 151.4(\mathrm{C}-3 \mathrm{a}), 143.5(\mathrm{C}-2)$, 142.7 (C-7a), 138.1 (C-11), 136.7 (C-17), 136.3 (C-6), 130.2 (C-18 and C-22), 129.7 (C-8a, C-19 and C-21), 128.1 (C-11a), 127.5 (C-20), 126.2 (C-4), 124.0 (C-5), 122.8 (C-10), 122.0 (C-11b), 119.1 (C-7), 117.3 (C-9), 115.5 (C-3b), 105.7 (C-3), 43.8 (C-16), 39.5 (C-13), 31.7 (C-12); (+)-ESIMS m/z $396[\mathrm{M}+\mathrm{H}]^{+} ;(+)$-HRESIMS $[\mathrm{M}+\mathrm{H}]^{+} 396.1701$ (calcd. for $\mathrm{C}_{25} \mathrm{H}_{22} \mathrm{~N}_{3} \mathrm{O}_{2}, 396.1707$ ).

\subsubsection{Styelsamine- $N^{14}-3$-phenylpropanamide (37)}

Using the general procedure, reaction of $N$-(3,4-dihydroxyphenethyl)-3-phenylpropanamide (32) ( $80.0 \mathrm{mg}, 0.28 \mathrm{mmol})$ with kynuramine dihydrobromide $(96.0 \mathrm{mg}, 0.30 \mathrm{mmol}), \mathrm{CeCl}_{3} \cdot 7 \mathrm{H}_{2} \mathrm{O}(15.0 \mathrm{mg}$, $0.04 \mathrm{mmol})$ and $\mathrm{Ag}_{2} \mathrm{O}(163 \mathrm{mg}, 0.70 \mathrm{mmol})$ afforded, after RP-2 column chromatography, 37 as a purple oil (29.0 mg, 20\% yield).

IR $v_{\max }\left(\right.$ ATR) 3321, 1661, 1584, 1202, 1130, $1015 \mathrm{~cm}^{-1} ; R_{\mathrm{t}}=10.60 \mathrm{~min} ;{ }^{1} \mathrm{H}$ NMR (DMSO- $d_{6}$, $400 \mathrm{MHz}) \delta_{\mathrm{H}} 13.49(1 \mathrm{H}$, br s, NH-1), $11.48(1 \mathrm{H}$, br s, OH), $10.80(1 \mathrm{H}$, br s, NH-8), $8.46(1 \mathrm{H}, \mathrm{t}$, $J=5.6 \mathrm{~Hz}, \mathrm{NH}-14), 8.26(1 \mathrm{H}, \mathrm{d}, J=6.4 \mathrm{~Hz}, \mathrm{H}-2), 8.22(1 \mathrm{H}, \mathrm{d}, J=8.0 \mathrm{~Hz}, \mathrm{H}-4), 7.71(2 \mathrm{H}, \mathrm{d}, J=4.0 \mathrm{~Hz}$, 
H-6 and H-7), $7.55(1 \mathrm{H}, \mathrm{d}, J=6.4 \mathrm{~Hz}, \mathrm{H}-3), 7.45(1 \mathrm{H}, \mathrm{s}, \mathrm{H}-10), 7.28-7.14(6 \mathrm{H}, \mathrm{m}, \mathrm{H}-5, \mathrm{H}-19$, $\mathrm{H}-20, \mathrm{H}-21, \mathrm{H}-22$ and H-23), $3.28\left(2 \mathrm{H}, \mathrm{dt}, J=6.8,5.6 \mathrm{~Hz}, \mathrm{H}_{2}-13\right), 2.96\left(2 \mathrm{H}, \mathrm{t}, J=6.8 \mathrm{~Hz}, \mathrm{H}_{2}-12\right)$, $2.85\left(2 \mathrm{H}, \mathrm{t}, J=7.6 \mathrm{~Hz}, \mathrm{H}_{2}-17\right), 2.45\left(2 \mathrm{H}, \mathrm{t}, J=7.6 \mathrm{~Hz}, \mathrm{H}_{2}-16\right) ;{ }^{13} \mathrm{C}$ NMR (DMSO- $\left.d_{6}, 100 \mathrm{MHz}\right) \delta_{\mathrm{C}}$ 173.2 (C-15), 149.2 (C-3a), 143.4 (C-2), 141.1 (C-7a and C-18), 136.7 (C-11), 135.0 (C-6), 128.3 (C-11a), 128.4 (C-8a), 128.2 (C-19, C-20, C-22 and C-23), 126.0 (C-21), 125.5 (C-4), 122.4 (C-5), 121.7 (C-10), 120.4 (C-11b), 117.7 (C-7), 116.2 (C-9), 113.9 (C-3b), 105.0 (C-3), 37.7 (C-13), 36.8 (C-16), 31.1 (C-17), 30.3 (C-12); (+)-ESIMS m/z $410[\mathrm{M}+\mathrm{H}]^{+}$; (+)-HRESIMS [M + H] 410.1875 (calcd. for $\mathrm{C}_{26} \mathrm{H}_{24} \mathrm{~N}_{3} \mathrm{O}_{2}, 410.1863$ ).

3.2.11.6. Styelsamine- $N^{14}$-palmitamide (38)

Using the general procedure, reaction of $N$-(3,4-dihydroxyphenethyl)palmitamide (33) (150.0 mg, $0.38 \mathrm{mmol}$ ) with kynuramine dihydrobromide (122 mg, $0.38 \mathrm{mmol}), \mathrm{CeCl}_{3} .7 \mathrm{H}_{2} \mathrm{O}(2.0 \mathrm{mg}, 0.05 \mathrm{mmol})$ and $\mathrm{Ag}_{2} \mathrm{O}(210 \mathrm{mg}, 0.89 \mathrm{mmol})$ afforded, after RP-18 column chromatography, 38 as a purple oil (40 mg, 16\% yield).

IR $v_{\max }$ (ATR) 3286, 3074, 2917, 1685, 1560, 1511, 1467, $1200 \mathrm{~cm}^{-1} ;{ }^{1} \mathrm{H}$ NMR $\left(\mathrm{CD}_{3} \mathrm{OD}, 400 \mathrm{MHz}\right)$ $\delta_{\mathrm{H}} 8.13(2 \mathrm{H}, \mathrm{d}, J=6.4 \mathrm{~Hz}, \mathrm{H}-2$ and H-4), 7.74-7.67 (2H, m, H-6 and H-7), 7.47 (1H, d, $J=6.8 \mathrm{~Hz}, \mathrm{H}-3)$, $7.42(1 \mathrm{H}, \mathrm{s}, \mathrm{H}-10), 7.27(1 \mathrm{H}, \mathrm{t}, J=7.4 \mathrm{~Hz}, \mathrm{H}-5), 3.37\left(2 \mathrm{H}, \mathrm{t}, J=7.6 \mathrm{~Hz}, \mathrm{H}_{2}-13\right), 3.06(2 \mathrm{H}, \mathrm{t}, J=7.6 \mathrm{~Hz}$, $\left.\mathrm{H}_{2}-12\right), 2.26-2.24$ (2H, m, $\left.\mathrm{H}_{2}-16\right), 1.65$ (2H, t, $\left.J=7.2 \mathrm{~Hz}, \mathrm{H}_{2}-17\right), 1.28$ (24H, br s, $\left.\mathrm{H}_{2}-18-\mathrm{H}_{2}-29\right), 0.87$ $\left(3 \mathrm{H}, J=7.2 \mathrm{~Hz}, \mathrm{H}_{3}-30\right) ;{ }^{13} \mathrm{C} \mathrm{NMR}\left(\mathrm{CD}_{3} \mathrm{OD}, 100 \mathrm{MHz}\right) \delta_{\mathrm{C}} 177.8(\mathrm{C}-15), 151.7(\mathrm{C}-3 \mathrm{a}), 143.7(\mathrm{C}-2)$, 142.9 (C-7a), 138.2 (C-11), 136.4 (C-6), 130.4 (C-8a), 127.8 (C-11a), 126.3 (C-4), 124.1 (C-5), 122.9 (C-10), 122.3 (C-11b), 119.2 (C-7), 117.6 (C-9), 115.7 (C-3b), 105.8 (C-3), 39.4 (C-13), 37.0 (C-16), 33.1 (C-28), 32.1 (C-12), 30.8 (C-18-C-27), 26.9 (C-17), 23.8 (C-29), 14.5 (C-30); (+)-ESIMS m/z $516[\mathrm{M}+\mathrm{H}]^{+}$; (+)-HRESIMS $[\mathrm{M}+\mathrm{H}]^{+} 516.3589$ (calcd. for $\mathrm{C}_{33} \mathrm{H}_{46} \mathrm{~N}_{3} \mathrm{O}_{2}, 516.3585$ ).

\subsubsection{General Procedure for the Preparation of $N$-Acyl Cystodytin Analogues 1, 10, 39-42}

To a stirring solution of styelsamine analogue (1 equiv.) in $\mathrm{MeOH}\left(1.0 \mathrm{~mL}\right.$ ) was added $\operatorname{Ag}_{2} \mathrm{O}$ (1.5 equiv.) followed by sat. $\mathrm{NaHCO}_{3}(3 \mathrm{~mL})$ dropwise. The purple mixture turned to red/orange then to yellow/green. The mixture was filtered, $\mathrm{H}_{2} \mathrm{O}(1.0 \mathrm{~mL})$ and EtOAc $(5.0 \mathrm{~mL})$ added and the organic phase separated and dried in vacuo to afford the product as a yellow oil or solid.

\subsubsection{Cystodytin J (10)}

Using the general procedure, reaction of styelsamine $\mathrm{B}(\mathbf{1 3})(7.0 \mathrm{mg}, 0.016 \mathrm{mmol})$ with $\mathrm{Ag}_{2} \mathrm{O}$ (5.0 mg, $0.022 \mathrm{mmol}$ ) afforded $\mathbf{1 0}$ as a yellow oil (4.0 $\mathrm{mg}, 79 \%$ yield) [10].

${ }^{1} \mathrm{H}$ NMR $\left(\mathrm{CDCl}_{3}, 400 \mathrm{MHz}\right) \delta_{\mathrm{H}} 8.94(1 \mathrm{H}, \mathrm{d}, J=5.3 \mathrm{~Hz}, \mathrm{H}-2), 8.59(1 \mathrm{H}, \mathrm{d}, J=8.1 \mathrm{~Hz}, \mathrm{H}-4), 8.55$ $(1 \mathrm{H}, \mathrm{d}, J=5.3 \mathrm{~Hz}, \mathrm{H}-3), 8.32(1 \mathrm{H}, \mathrm{dd}, J=8.4,1.1 \mathrm{~Hz}, \mathrm{H}-7), 7.91(1 \mathrm{H}, \mathrm{dt}, J=8.4,1.4 \mathrm{~Hz}, \mathrm{H}-6), 7.83$ $(1 \mathrm{H}, \mathrm{dt}, J=8.1,1.1 \mathrm{~Hz}, \mathrm{H}-5), 6.95(1 \mathrm{H}, \mathrm{s}, \mathrm{H}-10), 3.78\left(2 \mathrm{H}, \mathrm{dt}, J=6.4,6.4 \mathrm{~Hz}, \mathrm{H}_{2}-13\right), 3.32(2 \mathrm{H}, \mathrm{t}$, $\left.J=6.4 \mathrm{~Hz}, \mathrm{H}_{2}-12\right), 1.59\left(3 \mathrm{H}, \mathrm{s}, \mathrm{H}_{3}-16\right)$; (+)-ESIMS m/z $318[\mathrm{M}+\mathrm{H}]^{+}$; (+)-HRESIMS [M + H $]^{+}$ 318.1230 (calcd. for $\mathrm{C}_{19} \mathrm{H}_{16} \mathrm{~N}_{3} \mathrm{O}_{2}, 318.1237$ ). ${ }^{1} \mathrm{H}$ NMR data agreed with literature [4]. 


\subsubsection{Cystodytin A (1)}

Using the general procedure, reaction of styelsamine analogue $34(15.0 \mathrm{mg}, 0.032 \mathrm{mmol})$ with $\mathrm{Ag}_{2} \mathrm{O}(8.0 \mathrm{mg}, 0.042 \mathrm{mmol})$ afforded 1 as a yellow oil $(7.0 \mathrm{mg}, 62 \%$ yield $)$.

${ }^{1} \mathrm{H}$ NMR $\left(\mathrm{CDCl}_{3}, 400 \mathrm{MHz}\right) \delta_{\mathrm{H}} 9.24(1 \mathrm{H}, \mathrm{d}, J=5.6 \mathrm{~Hz}, \mathrm{H}-2), 8.60(1 \mathrm{H}, \mathrm{dd}, J=7.8,1.4 \mathrm{~Hz}, \mathrm{H}-4)$, $8.57(2 \mathrm{H}, \mathrm{d}, J=5.6 \mathrm{~Hz}, \mathrm{H}-3), 8.32(1 \mathrm{H}, \mathrm{dd}, J=7.8,1.0 \mathrm{~Hz}, \mathrm{H}-7), 7.94$ (1H, dt, $J=7.8,1.4 \mathrm{~Hz}, \mathrm{H}-6)$, $7.85(1 \mathrm{H}, \mathrm{dt}, J=7.8,1.0 \mathrm{~Hz}, \mathrm{H}-5), 6.95(1 \mathrm{H}, \mathrm{s}, \mathrm{H}-10), 5.85(1 \mathrm{H}, \mathrm{br} \mathrm{s}, \mathrm{NH}-14), 5.50(1 \mathrm{H}, \mathrm{s}, \mathrm{H}-16), 3.81$ $\left(2 \mathrm{H}, \mathrm{dt}, J=6.4,6.4 \mathrm{~Hz}, \mathrm{H}_{2}-13\right), 3.36\left(2 \mathrm{H}, \mathrm{t}, J=6.4 \mathrm{~Hz}, \mathrm{H}_{2}-12\right), 2.10\left(3 \mathrm{H}, \mathrm{s}, \mathrm{H}_{3}-19\right), 1.79$ (3H, s, $\mathrm{H}_{3}-18$ ); (+)-ESIMS $m / z 358[\mathrm{M}+\mathrm{H}]^{+}$; (+)-HRESIMS [M + H] 358.1544 (calcd. for $\mathrm{C}_{22} \mathrm{H}_{20} \mathrm{~N}_{3} \mathrm{O}_{2}$, 358.1550). ${ }^{1} \mathrm{H}$ NMR data agreed with literature [2].

\subsubsection{Cystodytin- $N^{14}$-benzamide (39)}

Using the general procedure, reaction of styelsamine analogue $35(20.0 \mathrm{mg}, 0.040 \mathrm{mmol})$ with $\mathrm{Ag}_{2} \mathrm{O}$ (12.0 mg, $\left.0.053 \mathrm{mmol}\right)$ afforded 39 as a yellow oil ( $8.00 \mathrm{mg}, 52 \%$ yield).

$R_{\mathrm{f}}\left(5 \% \mathrm{MeOH} / \mathrm{CH}_{2} \mathrm{Cl}_{2}\right)$ 0.37; IR $v_{\max }$ (smear) 3298, 1653, 1550, 1432, 1202, $766 \mathrm{~cm}^{-1} ;{ }^{1} \mathrm{H}$ NMR $\left(\mathrm{CDCl}_{3}, 400 \mathrm{MHz}\right) \delta_{\mathrm{H}} 9.24(1 \mathrm{H}, \mathrm{d}, J=5.6 \mathrm{~Hz}, \mathrm{H}-2), 8.60(1 \mathrm{H}, \mathrm{d}, J=7.6 \mathrm{~Hz}, \mathrm{H}-4), 8.58(1 \mathrm{H}, \mathrm{d}$, $J=5.6 \mathrm{~Hz}, \mathrm{H}-3), 8.30(1 \mathrm{H}, \mathrm{d}, J=8.2 \mathrm{~Hz}, \mathrm{H}-7), 7.93(1 \mathrm{H}, \mathrm{dt}, J=8.2,1.2 \mathrm{~Hz}, \mathrm{H}-6), 7.86(1 \mathrm{H}, \mathrm{t}$, $J=7.6 \mathrm{~Hz}, \mathrm{H}-5), 7.65(2 \mathrm{H}, \mathrm{d}, J=7.7 \mathrm{~Hz}, \mathrm{H}-17$ and H-21), $7.42(1 \mathrm{H}, \mathrm{t}, J=1.1 \mathrm{~Hz}, \mathrm{H}-19), 7.31(2 \mathrm{H}, \mathrm{t}$, $J=7.7 \mathrm{~Hz}, \mathrm{H}-18$ and H-20), $7.01(1 \mathrm{H}, \mathrm{s}, \mathrm{H}-10), 6.86(1 \mathrm{H}$, br s, NH-14), $3.98(2 \mathrm{H}, \mathrm{dt}, J=6.4,6.4 \mathrm{~Hz}$, $\left.\mathrm{H}_{2}-13\right), 3.44\left(2 \mathrm{H}, \mathrm{t}, J=6.4 \mathrm{~Hz}, \mathrm{H}_{2}-12\right) ;{ }^{13} \mathrm{C} \mathrm{NMR}\left(\mathrm{CDCl}_{3}, 100 \mathrm{MHz}\right) \delta_{\mathrm{C}} 181.8(\mathrm{C}-11), 173.8(\mathrm{C}-15)$, 152.7 (C-9), 151.6 (C-8a), 149.7 (C-2), 147.1 (C-11a), 145.3 (C-7a), 137.5 (C-3a), 134.4 (C-16), 132.1 (C-10), 131.9 (C-7), 131.3 (C-6), 131.2 (C-18 and C-20), 129.8 (C-5), 128.5 (C-19), 126.5 (C-17 and C-21), 123.0 (C-4), 121.4 (C-3b), 119.3 (C-3), 118.4 (C-11b), 40.0 (C-13), 31.0 (C-12); (+)-ESIMS $m / z 380[\mathrm{M}+\mathrm{H}]^{+} ;(+)$-HRESIMS [M $\left.+\mathrm{H}\right]^{+} 380.1411$ (calcd. for $\mathrm{C}_{24} \mathrm{H}_{18} \mathrm{~N}_{3} \mathrm{O}_{2} 380.1394$ ).

\subsubsection{Cystodytin- $N^{14}-2$-phenylacetamide (40)}

Using the general procedure, reaction of styelsamine analogue $36(21.0 \mathrm{mg}, 0.041 \mathrm{mmol})$ with $\mathrm{Ag}_{2} \mathrm{O}$ (12.0 mg, $\left.0.053 \mathrm{mmol}\right)$ afforded 40 as a yellow oil (2.1 $\mathrm{mg}, 13 \%$ yield).

$R_{\mathrm{f}}\left(5 \% \mathrm{MeOH} / \mathrm{CH}_{2} \mathrm{Cl}_{2}\right) \quad 0.25$; IR $v_{\max }$ (smear) 3290, 2924, 1657, 1585, 1432, 1201, $722 \mathrm{~cm}^{-1}$; ${ }^{1} \mathrm{H}$ NMR $\left(\mathrm{CDCl}_{3}, 400 \mathrm{MHz}\right) \delta_{\mathrm{H}} 9.23(1 \mathrm{H}, \mathrm{d}, J=5.3 \mathrm{~Hz}, \mathrm{H}-2), 8.58(1 \mathrm{H}, \mathrm{d}, J=7.8 \mathrm{~Hz}, \mathrm{H}-4), 8.55(1 \mathrm{H}$, $\mathrm{d}, J=6.6 \mathrm{~Hz}, \mathrm{H}-3), 8.25(1 \mathrm{H}, \mathrm{d}, J=7.9 \mathrm{~Hz}, \mathrm{H}-7), 7.92(1 \mathrm{H}, \mathrm{t}, J=7.9 \mathrm{~Hz}, \mathrm{H}-6), 7.84(1 \mathrm{H}, \mathrm{t}, J=6.6 \mathrm{~Hz}$, H-5), 7.21-7.18 (2H, m, H-19 and H-21), 7.16-7.11 (3H, m, H-18, H-20 and H-22), 6.81 (1H, s, H-10), 5.74 (1H, s, NH-14), 3.78-3.72 (2H, m, H2-13), $3.52\left(2 \mathrm{H}, \mathrm{s}, \mathrm{H}_{2}-16\right), 3.25$ (2H, t, $\left.J=6.3 \mathrm{~Hz}, \mathrm{H}_{2}-12\right)$; ${ }^{13} \mathrm{C} \mathrm{NMR}\left(\mathrm{CDCl}_{3}, 100 \mathrm{MHz}\right) \delta_{\mathrm{C}} 183.4(\mathrm{C}-11), 171.2(\mathrm{C}-15), 151.8(\mathrm{C}-9), 150.3(\mathrm{C}-8 \mathrm{a}), 150.0(\mathrm{C}-2)$, 147.2 (C-11a), 145.4 (C-7a), 137.8 (C-3a), 134.6 (C-17), 132.8 (C-10), 132.0 (C-7), 131.7 (C-6), 129.9 (C-5), 129.3 (C-19 and C-21), 129.0 (C-18 and C-22), 127.3 (C-20), 122.9 (C-4), 121.9 (C-3b), 119.3 (C-3), 118.5 (C-11b), 43.8 (C-16), 39.3 (C-13), 31.3 (C-12); (+)-ESIMS m/z $394[\mathrm{M}+\mathrm{H}]^{+}$; (+)-HRESIMS $[\mathrm{M}+\mathrm{H}]^{+} 394.1552$ (calcd. for $\mathrm{C}_{25} \mathrm{H}_{20} \mathrm{~N}_{3} \mathrm{O}_{2} 394.1550$ ). 


\subsubsection{Cystodytin- $N^{14}-3$-phenylpropanamide (41)}

Using the general procedure, reaction of styelsamine analogue 37 (9.0 mg, $0.017 \mathrm{mmol})$ with $\mathrm{Ag}_{2} \mathrm{O}$ (5.0 mg, $0.022 \mathrm{mmol}$ ) afforded 41 as a yellow oil (5.0 $\mathrm{mg}, 71 \%$ yield).

$R_{\mathrm{f}}\left(5 \% \mathrm{MeOH} / \mathrm{CH}_{2} \mathrm{Cl}_{2}\right)$ 0.13; IR $v_{\max }$ (smear) 3285, 3072, 2922, 1647, 1551, 1588, $1332 \mathrm{~cm}^{-1}$; ${ }^{1} \mathrm{H} \mathrm{NMR}\left(\mathrm{CDCl}_{3}, 400 \mathrm{MHz}\right) \delta_{\mathrm{H}} 9.20(1 \mathrm{H}, \mathrm{d}, J=5.5 \mathrm{~Hz}, \mathrm{H}-2), 8.59(1 \mathrm{H}, \mathrm{dd}, J=7.6,1.4 \mathrm{~Hz}, \mathrm{H}-4), 8.51$ $(1 \mathrm{H}, \mathrm{d}, J=5.5 \mathrm{~Hz}, \mathrm{H}-3), 8.28$ (1H, dd, $J=7.6,1.1 \mathrm{~Hz}, \mathrm{H}-7), 7.94(1 \mathrm{H}, \mathrm{dt}, J=7.6,1.4 \mathrm{~Hz}, \mathrm{H}-6), 7.85$ $(1 \mathrm{H}, \mathrm{t}, J=7.6,1.1 \mathrm{~Hz}, \mathrm{H}-5), 7.13(2 \mathrm{H}, \mathrm{td}, J=7.5,1.5 \mathrm{~Hz}, \mathrm{H}-20$ and $\mathrm{H}-22), 7.09-7.07$ (2H, m, H-19 and $\mathrm{H}-23), 7.03(1 \mathrm{H}, \mathrm{tt}, J=7.1,1.4 \mathrm{~Hz}, \mathrm{H}-21), 6.86(1 \mathrm{H}, \mathrm{s}, \mathrm{H}-10), 6.05(1 \mathrm{H}, \mathrm{br} \mathrm{s}, \mathrm{NH}-14), 3.75(2 \mathrm{H}$, $\left.\mathrm{dt}, J=6.2,6.2, \mathrm{H}_{2}-13\right), 3.24\left(2 \mathrm{H}, \mathrm{t}, J=6.2 \mathrm{~Hz}, \mathrm{H}_{2}-12\right), 2.89\left(2 \mathrm{H}, \mathrm{t}, J=7.6 \mathrm{~Hz}, \mathrm{H}_{2}-17\right), 2.44(2 \mathrm{H}, \mathrm{t}$, $\left.J=7.6 \mathrm{~Hz}, \mathrm{H}_{2}-16\right) ;{ }^{13} \mathrm{C} \mathrm{NMR}\left(\mathrm{CDCl}_{3}, 100 \mathrm{MHz}\right) \delta_{\mathrm{C}} 184.0(\mathrm{C}-11), 172.4(\mathrm{C}-15), 152.2(\mathrm{C}-9), 150.7$ (C-8a), 150.2 (C-2), 147.0 (C-11a), 145.5 (C-7a), 140.9 (C-18), 137.4 (C-3a), 133.0 (C-10), 132.0 (C-6 and C-7), 130.1 (C-5), 128.5 (C-20 and C-22), 128.4 (C-19 and C-23), 126.3 (C-21), 123.1 (C-4), 122.1 (C-3b), 119.4 (C-3), 118.3 (C-11b), 39.5 (C-13), 38.7 (C-16), 31.9 (C-17), 31.6 (C-12); $(+)$-ESIMS $m / z 407[\mathrm{M}+\mathrm{H}]^{+}$; (+)-HRESIMS $[\mathrm{M}+\mathrm{H}]^{+} 408.1716$ (calcd. for $\mathrm{C}_{26} \mathrm{H}_{22} \mathrm{~N}_{3} \mathrm{O}_{2}, 408.1707$ ).

\subsubsection{Cystodytin- $N^{14}$-palmitamide (42)}

Using the general procedure, reaction of styelsamine analogue $38(37.0 \mathrm{mg}, 0.059 \mathrm{mmol})$ with $\mathrm{Ag}_{2} \mathrm{O}$ (17.0 mg, $\left.0.072 \mathrm{mmol}\right)$ afforded 42 as a yellow oil (5.2 $\mathrm{mg}, 17 \%$ yield).

$R_{\mathrm{f}}\left(5 \% \mathrm{MeOH} / \mathrm{CH}_{2} \mathrm{Cl}_{2}\right)$ 0.31; IR $v_{\max }$ (smear) 3303, 2914, 2849, 1656, 1553, 1470, $774 \mathrm{~cm}^{-1} ;{ }^{1} \mathrm{H}$ NMR $\left(\mathrm{CDCl}_{3}, 400 \mathrm{MHz}\right) \delta_{\mathrm{H}} 9.25(1 \mathrm{H}, \mathrm{d}, J=5.5 \mathrm{~Hz}, \mathrm{H}-2), 8.61(1 \mathrm{H}, \mathrm{dd}, J=8.1,1.4 \mathrm{~Hz}, \mathrm{H}-4), 8.58$ $(1 \mathrm{H}, \mathrm{d}, J=5.5 \mathrm{~Hz}, \mathrm{H}-3), 8.32(1 \mathrm{H}, \mathrm{dd}, J=7.5,1.3 \mathrm{~Hz}, \mathrm{H}-7), 7.95(1 \mathrm{H}, \mathrm{td}, J=7.5,1.4 \mathrm{~Hz}, \mathrm{H}-6), 7.84$ $(1 \mathrm{H}, \mathrm{td}, J=8.1,1.3 \mathrm{~Hz}, \mathrm{H}-5), 6.95(1 \mathrm{H}, \mathrm{s}, \mathrm{H}-10), 6.01(1 \mathrm{H}, \mathrm{s}, \mathrm{NH}-14), 3.79$ (2H, dt, $J=6.4,6.4 \mathrm{~Hz}$, $\left.\mathrm{H}_{2}-13\right), 3.32\left(2 \mathrm{H}, \mathrm{t}, J=6.4 \mathrm{~Hz}, \mathrm{H}_{2}-12\right), 2.11\left(2 \mathrm{H}, \mathrm{d}, J=7.4 \mathrm{~Hz}, \mathrm{H}_{2}-16\right), 1.55\left(2 \mathrm{H}\right.$, br s, $\left.\mathrm{H}_{2}-17\right), 1.25$

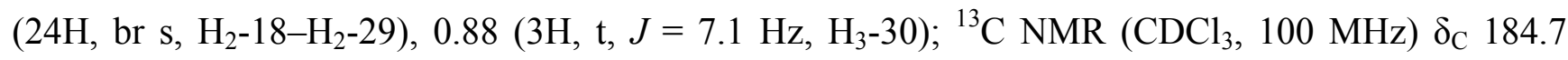
(C-11), 173.4 (C-15), 151.9 (C-9), 150.6 (C-8a), 150.2 (C-2), 146.9 (C-11a), 145.5 (C-7a), 137.5 (C-3a), 133.0 (C-10), 132.0 (C-6 and C-7), 130.1 (C-5), 123.3 (C-4), 122.0 (C-3b), 119.5 (C-3), 117.2 (C-11b), 39.5 (C-13), 37.0 (C-16), 32.1 (C-28), 31.8 (C-12), 29.6 (C-18-C-27), 25.9 (C-17), 22.8 (C-29), 14.3 (C-30); (+)-ESIMS m/z $514[\mathrm{M}+\mathrm{H}]^{+}$; (+)-HRESIMS [M + H] 514.3410 (calcd. for $\mathrm{C}_{33} \mathrm{H}_{44} \mathrm{~N}_{3} \mathrm{O}_{2}$ 514.3428).

\subsubsection{Styelsamine D Ditrifluoroacetate (15)}

Styelsamine B (13) $(35.1 \mathrm{mg}, 0.081 \mathrm{mmol})$ was dissolved in $1: 1 \mathrm{MeOH} / 4 \mathrm{~N} \mathrm{HCl}(10 \mathrm{~mL})$ and heated to $80{ }^{\circ} \mathrm{C}$. After $24 \mathrm{~h}$, the solvents were removed in vacuo and the product purified by RP-18 column chromatography $\left(\mathrm{H}_{2} \mathrm{O}(0.05 \%\right.$ TFA): $\mathrm{MeOH}(0.05 \%$ TFA) (100:0 to 85:15)) to afford 15 as a purple oil (30.5 mg, 75\% yield).

IR $v_{\max }$ (ATR) 3412, 1678, 1434, 1203, 1180, 1129, $765 \mathrm{~cm}^{-1} ; R_{\mathrm{t}}=4.68 \mathrm{~min} ;{ }^{1} \mathrm{H}$ NMR (DMSO- $d_{6}$, $400 \mathrm{MHz}) \delta_{\mathrm{H}} 13.85(1 \mathrm{H}, \mathrm{s}, \mathrm{NH}-1), 10.93(1 \mathrm{H}, \mathrm{br} \mathrm{s}, \mathrm{OH}), 8.32(1 \mathrm{H}, \mathrm{d}, J=6.8 \mathrm{~Hz}, \mathrm{H}-2), 8.25(1 \mathrm{H}, \mathrm{d}$, $J=7.4 \mathrm{~Hz}, \mathrm{H}-4), 8.03\left(3 \mathrm{H}\right.$, br s, $\left.\mathrm{NH}_{3}-15\right), 7.75-7.68(2 \mathrm{H}, \mathrm{m}, \mathrm{H}-6$ and $\mathrm{H}-7), 7.62(1 \mathrm{H}, \mathrm{d}, J=6.8 \mathrm{~Hz}$, H-3), 7.51 (1H, s, H-10), 7.25 (1H, dt, $J=7.4,1.5 \mathrm{~Hz}, \mathrm{H}-5), 3.23$ (2H, br t, $\left.J=7.5 \mathrm{~Hz}, \mathrm{H}_{2}-12\right), 3.12-3.11$ 
$\left(2 \mathrm{H}, \mathrm{m}, \mathrm{H}_{2}-13\right) ;{ }^{13} \mathrm{C}$ NMR (DMSO- $\left.d_{6}, 100 \mathrm{MHz}\right) \delta_{\mathrm{C}} 149.5$ (C-3a), 143.6 (C-2), 141.5 (C-7a), 137.4 (C-11), 134.9 (C-6), 128.6 (C-8a), 126.8 (C-11a), 125.5 (C-4), 122.2 (C-5), 121.3 (C-10), 120.8 (C-11b), 118.1 (C-7), 114.2 (C-3b), 113.3 (C-9), 105.4 (C-3), 38.2 (C-13), 28.6 (C-12); (+)-ESIMS m/z 278 $[\mathrm{M}+\mathrm{H}]^{+} ;(+)$-HRESIMS $[\mathrm{M}+\mathrm{H}]^{+} 278.1298$ (calcd. for $\mathrm{C}_{17} \mathrm{H}_{16} \mathrm{~N}_{3} \mathrm{O}, 278.1288$ ). ${ }^{1} \mathrm{H}$ and ${ }^{13} \mathrm{C}$ NMR data agreed with literature [6].

3.2.14. O-Methyl Styelsamine D Ditrifluoroacetate (43)

Styelsamine B (13) $(19.0 \mathrm{mg}, 0.044 \mathrm{mmol})$ was dissolved in 1:1 $\mathrm{MeOH} / 4 \mathrm{~N} \mathrm{HCl}(10 \mathrm{~mL})$ and heated to $80^{\circ} \mathrm{C}$. After $48 \mathrm{~h}$, solvents were removed in vacuo and the residue purified by RP-18 column chromatography to afford $\mathbf{1 5}$ as a purple oil (13.4 mg, 60\% yield) and $\mathbf{4 3}$ as a purple oil (10.3 $\mathrm{mg}$, $45 \%$ yield).

IR $v_{\max }$ (ATR) 3382, 1675, 1429, 1178, 1138, $765 \mathrm{~cm}^{-1} ; R_{\mathrm{t}}=4.90 \mathrm{~min} ;{ }^{1} \mathrm{H}$ NMR (DMSO- $d_{6}, 400 \mathrm{MHz}$ ) $\delta_{\mathrm{H}} 13.85(1 \mathrm{H}$, br s, NH-1), $11.37(1 \mathrm{H}$, br s, NH-8), $8.38(1 \mathrm{H}, \mathrm{d}, J=6.5 \mathrm{~Hz}, \mathrm{H}-2), 8.28(1 \mathrm{H}, \mathrm{d}, J=8.0 \mathrm{~Hz}$, $\mathrm{H}-4), 8.18$ (3H, br s, $\left.\mathrm{NH}_{3}-14\right), 8.04(1 \mathrm{H}, \mathrm{d}, J=8.3 \mathrm{~Hz}, \mathrm{H}-7), 7.79(1 \mathrm{H}, \mathrm{s}, \mathrm{H}-10), 7.73-7.70(2 \mathrm{H}, \mathrm{m}$, H-3 and H-6), 7.27 (1H, t, $J=8.0 \mathrm{~Hz}, \mathrm{H}-5), 4.06(3 \mathrm{H}, \mathrm{s}, \mathrm{OMe}), 3.38\left(2 \mathrm{H}, \mathrm{t}, J=7.2 \mathrm{~Hz}, \mathrm{H}_{2}-12\right), 3.14-3.12$ $\left(2 \mathrm{H}, \mathrm{m}, \mathrm{H}_{2}-13\right) ;{ }^{13} \mathrm{C}$ NMR (DMSO- $\left.d_{6}, 100 \mathrm{MHz}\right) \delta_{\mathrm{C}} 149.1$ (C-3a), 143.5 (C-2), 141.2 (C-7a), 138.7 (C-11), 135.0 (C-6), 129.6 (C-8a), 127.3 (C-11a), 125.5 (C-4), 122.7 (C-5), 120.1 (C-11b), 119.5 (C-10), 118.0 (C-7), 117.9 (C-9), 113.8 (C-3b), 106.0 (C-3), 56.9 (OMe), 37.9 (C-13), 28.4 (C-12); (+)-ESIMS m/z $292[\mathrm{M}+\mathrm{H}]^{+} ;(+)$-HRESIMS $[\mathrm{M}+\mathrm{H}]^{+} 292.1448$ (calcd. for $\mathrm{C}_{18} \mathrm{H}_{18} \mathrm{~N}_{3} \mathrm{O} 292.1444$ ).

\subsubsection{5. $O$-Methyl-styelsamine- $N^{14}-3$-methylbut-2-enamide Trifluoroacetate (46)}

To a solution of $O$-methyl styelsamine D (43) $(11.0 \mathrm{mg}, 0.021 \mathrm{mmol})$ in dry DMF (3 mL) was added 3,3-dimethylacrylic acid (5.96 mg, $0.060 \mathrm{mmol})$ and PyBOP (31.0 $\mathrm{mg}, 0.060 \mathrm{mmol}$ ) followed by $\mathrm{Et}_{3} \mathrm{~N}(22 \mu \mathrm{L}, 0.16 \mathrm{mmol})$. The solution was stirred under $\mathrm{N}_{2}$ at room temperature for $25 \mathrm{~h} . \mathrm{CH}_{2} \mathrm{Cl}_{2}$ $(20 \mathrm{~mL})$ was added, washed with $\mathrm{H}_{2} \mathrm{O}(15 \mathrm{~mL})$ and the organic phase dried in vacuo to give a purple/red oil. Purification using RP-2 column chromatography $\left(\mathrm{H}_{2} \mathrm{O}(0.05 \%\right.$ TFA):MeOH (0.05\% TFA) (100:0 to 40:60)) afforded 46 as a purple oil ( $9.1 \mathrm{mg}, 88 \%$ yield).

IR $v_{\max }$ (ATR) 3396, 1675, 1586, 1433, 1182, 1134, $765 \mathrm{~cm}^{-1} ; R_{\mathrm{t}}=7.58 \mathrm{~min} ;{ }^{1} \mathrm{H}$ NMR (DMSO- $d_{6}$, $400 \mathrm{MHz}) \delta_{\mathrm{H}} 13.78(1 \mathrm{H}$, br s, NH-1), $11.85(1 \mathrm{H}, \mathrm{s}, \mathrm{NH}-8), 8.51(1 \mathrm{H}, \mathrm{t}, J=5.6 \mathrm{~Hz}, \mathrm{NH}-14), 8.34(1 \mathrm{H}$, $\mathrm{d}, J=6.5 \mathrm{~Hz}, \mathrm{H}-2), 8.28(1 \mathrm{H}, \mathrm{d}, J=8.2 \mathrm{~Hz}, \mathrm{H}-4), 7.79(1 \mathrm{H}, \mathrm{d}, J=7.9 \mathrm{~Hz}, \mathrm{H}-7), 7.76-7.72(2 \mathrm{H}, \mathrm{m}$, H-6 and H-10), $7.68(1 \mathrm{H}, \mathrm{d}, J=6.5 \mathrm{~Hz}, \mathrm{H}-3), 7.27(1 \mathrm{H}, \mathrm{td}, J=8.2,1.0 \mathrm{~Hz}, \mathrm{H}-5), 5.72(1 \mathrm{H}, \mathrm{s}, \mathrm{H}-16)$, $4.03(3 \mathrm{H}, \mathrm{s}, \mathrm{OMe}), 3.34\left(2 \mathrm{H}, \mathrm{dt}, J=7.2,5.6 \mathrm{~Hz}, \mathrm{H}_{2}-13\right), 3.08\left(2 \mathrm{H}, \mathrm{t}, J=7.2 \mathrm{~Hz}, \mathrm{H}_{2}-12\right), 2.16(3 \mathrm{H}, \mathrm{s}$, $\left.\mathrm{H}_{3}-19\right), 1.81\left(3 \mathrm{H}, \mathrm{s}, \mathrm{H}_{3}-18\right) ;{ }^{13} \mathrm{C}$ NMR (DMSO- $\left.d_{6}, 100 \mathrm{MHz}\right) \delta_{\mathrm{C}} 167.8(\mathrm{C}-15), 150.1(\mathrm{C}-17), 149.4$ (C-3a), 143.5 (C-2), 141.2 (C-7a), 138.5 (C-11), 135.2 (C-6), 129.5 (C-8a), 126.7 (C-11a), 125.7 (C-4), 122.7 (C-5), 119.9 (C-11b), 119.1 (C-10), 118.3 (C-16), 118.1 (C-7), 117.7 (C-9), 114.1 (C-3b), 105.7 (C-3), 56.9 (OMe), 37.4 (C-13), 30.6 (C-12), 26.9 (C-18), 19.5 (C-19); (+)-ESIMS m/z 374 [M + H] ; $(+)$-HRESIMS $[\mathrm{M}+\mathrm{H}]^{+} 374.1875$ (calcd. for $\mathrm{C}_{23} \mathrm{H}_{24} \mathrm{~N}_{3} \mathrm{O}_{2}, 374.1876$ ). ${ }^{1} \mathrm{H}$ NMR data agreed with literature [2]. 
3.2.16. $O$-Methyl-styelsamine- $N^{14}$-2-phenylacetamide Trifluoroacetate (47)

To a solution of $O$-methyl styelsamine D (43) $(11.0 \mathrm{mg}, 0.021 \mathrm{mmol})$ in dry DMF (2 mL) was added phenylacetic acid $(5.1 \mathrm{mg}, 0.038 \mathrm{mmol})$ and PyBOP $(19.0 \mathrm{mg}, 0.038 \mathrm{mmol})$ followed by $\mathrm{Et}_{3} \mathrm{~N}$ (16 $\mu \mathrm{L}, 0.11 \mathrm{mmol})$. The solution was stirred under $\mathrm{N}_{2}$ at room temperature for $1 \mathrm{~h} . \mathrm{CH}_{2} \mathrm{Cl}_{2}(10 \mathrm{~mL})$ was added, washed with $\mathrm{H}_{2} \mathrm{O}(10 \mathrm{~mL})$ and the organic phase dried in vacuo to give a purple/red oil. Purification using RP-2 column chromatography $\left(\mathrm{H}_{2} \mathrm{O}(0.05 \%\right.$ TFA):MeOH $(0.05 \%$ TFA) (100:0 to 50:50)) afforded 47 as a purple oil (5.28 mg, $48 \%$ yield).

IR $v_{\max }$ (ATR) 3394, 1679, 1584, 1489, 1140, 1052, $708 \mathrm{~cm}^{-1} ; R_{\mathrm{t}}=7.33 \mathrm{~min} ;{ }^{1} \mathrm{H}$ NMR (DMSO- $d_{6}$, $400 \mathrm{MHz}) \delta_{\mathrm{H}} 13.74(1 \mathrm{H}, \mathrm{s}, \mathrm{NH}-1), 11.39(1 \mathrm{H}, \mathrm{s}, \mathrm{NH}-8), 8.56(1 \mathrm{H}, \mathrm{t}, J=5.6 \mathrm{~Hz}, \mathrm{NH}-14), 8.35$ (1H, d, $J=6.5 \mathrm{~Hz}, \mathrm{H}-2), 8.27(1 \mathrm{H}, \mathrm{d}, J=8.2 \mathrm{~Hz}, \mathrm{H}-4), 7.76-7.74(1 \mathrm{H}, \mathrm{m}, \mathrm{H}-7), 7.73-7.71(2 \mathrm{H}, \mathrm{m}, \mathrm{H}-6$ and $\mathrm{H}-10), 7.68(1 \mathrm{H}, \mathrm{d}, J=6.5 \mathrm{~Hz}, \mathrm{H}-3), 7.29-7.26$ (1H, m, H-5), 7.29-7.23 (2H, m, H-18 and H-22), 7.23-7.19 (3H, m , H-19, H-20 and H-21), 4.00 (3H, s, OMe), 3.46 (2H, s, $\left.\mathrm{H}_{2}-16\right), 3.40$ (2H, dt, $\left.J=6.9,5.6 \mathrm{~Hz}, \mathrm{H}_{2}-13\right), 3.08\left(2 \mathrm{H}, \mathrm{t}, J=6.9 \mathrm{~Hz}, \mathrm{H}_{2}-12\right) ;{ }^{13} \mathrm{C}$ NMR (DMSO- $\left.d_{6}, 100 \mathrm{MHz}\right) \delta_{\mathrm{C}} 171.6$ (C-15), 149.2 (C-3a), 143.5 (C-2), 141.0 (C-7a), 138.5 (C-11), 136.0 (C-17), 135.2 (C-6), 129.4 (C-8a), 128.8 (C-18 and C-22), 128.2 (C-19 and C-21), 126.7 (C-11a), 126.4 (C-20), 125.6 (C-4), 122.7 (C-5), 119.9 (C-11b), 119.0 (C-10), 118.2 (C-7), 116.0 (C-9), 114.0 (C-3b), 105.7 (C-3), 56.9 (OMe), 42.2 (C-16), 37.6 (C-13), $30.1(\mathrm{C}-12)$; (+)-ESIMS m/z $410[\mathrm{M}+\mathrm{H}]^{+}$; (+)-HRESIMS [M + H] 410.1855 (calcd. for $\mathrm{C}_{26} \mathrm{H}_{24} \mathrm{~N}_{3} \mathrm{O}_{2}, 410.1863$ ).

\subsubsection{7. $O$-Methyl-styelsamine- $N^{14}-3$-phenylpropanamide Trifluoroacetate (48)}

To a cold $\left(0{ }^{\circ} \mathrm{C}\right)$ solution of $O$-methyl styelsamine D (43) $(7.0 \mathrm{mg}, 0.013 \mathrm{mmol})$ in dry THF $(2 \mathrm{~mL})$ was added dihydrocinnamoyl chloride $(5.64 \mu \mathrm{L}, 0.038 \mathrm{mmol})$ followed by $\mathrm{Et}_{3} \mathrm{~N}(7.1 \mu \mathrm{L}, 0.051 \mathrm{mmol})$. The solution was stirred under $\mathrm{N}_{2}$ at room temperature for $30 \mathrm{~min}$. Solvents were removed in vacuo to give a purple/red oil. Purification using RP-2 ( $\mathrm{H}_{2} \mathrm{O}(0.05 \%$ TFA): $\mathrm{MeOH}(0.05 \%$ TFA) (100:0 to 50:50)) and LH-20 column chromatography ( $\mathrm{MeOH}(0.05 \% \mathrm{TFA})$ ) afforded $\mathbf{4 8}$ as a purple oil (3.2 mg, $43 \%$ yield).

IR $v_{\max }$ (ATR) $3407,1679,1584,1489,1140,1052,701 \mathrm{~cm}^{-1} ; R_{\mathrm{t}}=7.85 \mathrm{~min} ;{ }^{1} \mathrm{H}$ NMR (DMSO- $d_{6}$, $400 \mathrm{MHz}) \delta_{\mathrm{H}} 13.69(1 \mathrm{H}, \mathrm{s}, \mathrm{NH}-1), 11.63(1 \mathrm{H}, \mathrm{s}, \mathrm{NH}-8), 8.49(1 \mathrm{H}, \mathrm{t}, J=5.5 \mathrm{~Hz}, \mathrm{NH}-14), 8.36$ (1H, d, $J=6.4 \mathrm{~Hz}, \mathrm{H}-2), 8.31(1 \mathrm{H}, \mathrm{d}, J=8.3 \mathrm{~Hz}, \mathrm{H}-4), 7.80-7.74(2 \mathrm{H}, \mathrm{m}, \mathrm{H}-6$ and H-7), $7.76(1 \mathrm{H}, \mathrm{s}, \mathrm{H}-10)$, $7.70(1 \mathrm{H}, \mathrm{d}, J=6.4 \mathrm{~Hz}, \mathrm{H}-3), 7.29(1 \mathrm{H}, \mathrm{dt}, J=8.3,2.2 \mathrm{~Hz}, \mathrm{H}-5), 7.24(2 \mathrm{H}, \mathrm{d}, J=7.4 \mathrm{~Hz}, \mathrm{H}-19$ and $\mathrm{H}-23), 7.21-7.15$ (3H, m, H-20, H-21 and 22), $4.04(3 \mathrm{H}, \mathrm{s}, \mathrm{OMe}), 3.33(2 \mathrm{H}, \mathrm{dt}, J=7.2,5.5 \mathrm{~Hz}$, $\left.\mathrm{H}_{2}-13\right), 3.03\left(2 \mathrm{H}, \mathrm{t}, J=7.2 \mathrm{~Hz}, \mathrm{H}_{2}-12\right), 2.86\left(2 \mathrm{H}, \mathrm{t}, J=7.7 \mathrm{~Hz}, \mathrm{H}_{2}-17\right), 2.47-2.45\left(2 \mathrm{H}, \mathrm{m}, \mathrm{H}_{2}-16\right) ;{ }^{13} \mathrm{C}$ NMR (DMSO- $\left.d_{6}, 100 \mathrm{MHz}\right) \delta_{\mathrm{C}} 173.3(\mathrm{C}-15), 149.2$ (C-3a), 143.5 (C-2), 141.0 (C-7a and C-18), 138.4 (C-11), 135.3 (C-6), 129.5 (C-8a), 128.2 (C-19, C-20, C-22 and C-23), 125.9 (C-11a and C-21), 125.7 (C-4), 122.7 (C-5), 119.9 (C-11b), 119.1 (C-10), 117.8 (C-7), 116.0 (C-9), 114.1 (C-3b), 105.7 (C-3), 56.9 (OMe), 37.5 (C-13), 36.8 (C-16), 31.0 (C-17), 30.3 (C-12); (+)-ESIMS m/z $424[\mathrm{M}+\mathrm{H}]^{+}$; $(+)$-HRESIMS $[\mathrm{M}+\mathrm{H}]^{+} 424.2005$ (calcd. for $\mathrm{C}_{27} \mathrm{H}_{26} \mathrm{~N}_{3} \mathrm{O}_{2}, 424.2020$ ). 


\subsection{Biological Assays}

\subsubsection{Ethidium Bromide Displacement Assay}

\subsubsection{Preparation of Solutions}

An acetate buffer solution ( $\mathrm{pH}$ 5) was prepared daily using $\mathrm{NaOAc}(2 \mathrm{mM}), \mathrm{NaCl}(9.3 \mathrm{mM})$ and $\mathrm{Na}_{2}$ EDTA $(0.1 \mathrm{mM})$. The acetate buffer was preferred in this displacement assay as the compounds being tested are easily oxidized (de-protonated); an instant color change from purple to yellow was observed in a pH 7 SHE buffer solution ( $\mathrm{NaCl}[9.4 \mathrm{mM}]$, EDTA [20 $\mu \mathrm{M}]$ and HEPES [2 nM]) while a color change occur only after one and a half hours in acetate buffer solution. A stock solution of ethidium bromide $(1.26 \mathrm{mM})$ was prepared by dissolving ethidium bromide $(0.5 \mathrm{mg})$ in $1 \mathrm{~mL}$ of acetate buffer. A volume of $3 \mu \mathrm{L}$ is required to make up a $3 \mathrm{~mL}$ DNA-ethidium bromide solution to give $1.26 \mu \mathrm{M}$ of ethidium bromide.

The stock solutions of calf thymus DNA (CT-DNA) was prepared in an acetate buffer daily and then diluted down until absorbance of the CT-DNA at $260 \mathrm{~nm}$ is less than 1 absorbance unit. The concentration of CT-DNA solution was calculated in base pairs using the formula $A=\varepsilon c l$ (absorbance, $A$; absorption coefficient, $\varepsilon, 13200$ in base pairs [or 6600 in nucleotides] for CT-DNA; concentration, $c$, moles per liter; path length, $l, 1 \mathrm{~cm}$ ) [16]. Experiments that used a stock solution of CT-DNA that was older than four days were found to have lower initial fluorescence intensity, possibly due to the CT-DNA becoming partially hydrolyzed or depurinated, requiring the CT-DNA solution to be prepared daily. Once the concentration of the stock solution of CT-DNA was determined, the appropriate volume needed to make up a $3 \mathrm{~mL}$ DNA-ethidium bromide solution to give a total concentration of $1 \mu \mathrm{M}$ of CT-DNA was then calculated.

The test compounds were prepared to a concentration of $1 \mathrm{mM}$ using acetate buffer. In some cases (as indicated in Table 1) DMSO (up to $0.5 \%$ total volume) was also used if required to dissolve certain compounds.

\subsubsection{General Methods for Competitive Ethidium Bromide Displacement Assay}

All UV and fluorescence measurements were performed in $3 \mathrm{~mL}$ quartz cuvettes. Absorbance of CT-DNA solutions were measured using either a UV-2101 PC UV-VIS scanning Shimadzu Spectrophotometer or a Perkin-Elmer Lambda 35 UV/VIS spectrometer (at $260 \mathrm{~nm}$ ). Fluorescence intensity for the ethidium bromide displacement assays were measured using a Perkin-Elmer LS 55 Luminescence Spectrometer (emission at $546 \mathrm{~nm}$; excitation at $595 \mathrm{~nm}$; emission slits at 10; excitation slits at 5). All solution used were at room temperature and stored in a freezer when they were not required.

All glassware was washed with deionized $\mathrm{H}_{2} \mathrm{O}$ and dried with $\mathrm{N}_{2}$ gas before each experiment. Six DNA-ethidium bromide solutions were prepared by dilution with the acetate buffer to contain $1 \mu \mathrm{M}$ CT-DNA and $1.26 \mu \mathrm{M}$ ethidium bromide to make up a $3 \mathrm{~mL}$ solution. Each DNA-ethidium bromide solution was well mixed before measuring the initial florescence of the DNA-ethidium bromide solution in the cuvette. The fluorescence was reported as an average of five readings. Different volumes (constant differences, e.g., 3, 6, 9, 12, 15, $18 \mu \mathrm{L}$ ) of the test compound (1 mM) were added to 
each of the DNA-ethidium bromide test solutions. After equilibration for $15 \mathrm{~min}$, the fluorescence of the solutions was measured in the order from lowest concentration to the highest concentration of test compound and reported from an average of five readings. Sets of volumes were screened until the fluorescence was below $50 \%$ of the initial reading. Once the volume was determined, the assay was repeated twice more to get an uncertainty value. Dilution effect was taken into consideration when the volume change is greater than $5 \%$ and fluorescence was corrected using the formula $F_{\text {corr }}=F_{\exp } \times(3000+\mathrm{V}) / 3000$ [where $\mathrm{V}$ is the volume (in $\left.\mu \mathrm{L}\right)$ of the compound added]. $\mathrm{C}_{50}$, concentration $(\mu \mathrm{M})$ of compound required to reduce the fluorescence by $50 \%$, was interpolated by graphing the concentration of the test compound versus the observed fluorescence. The apparent binding constants $\left(K_{\text {app }}\right)$ were calculated as follows: $K_{\text {app }}=\left(1.26 / \mathrm{C}_{50}\right) \times K_{\text {ethidium}}$, with a value of $K_{\text {ethidium }}=2.1 \times 10^{6} \mathrm{M}(\mathrm{bp})^{-1}[16]$.

\subsubsection{Antitumor Testing}

Details of the testing of compounds for antitumor activity under the auspices of the Developmental Therapeutics Program NCI/NIH are available elsewhere [27].

\section{4. cLogP Calculations}

The $\log$ P calculations were performed using the ALOGPS 2.1 software package $[17,18]$.

\section{Conclusions}

A series of natural and un-natural analogues of the pyrido[4,3,2-mn]acridine styelsamine and pyridoacridone cystodytin marine natural products were prepared and evaluated for DNA binding affinity and whole cell antiproliferative properties against a panel of human tumor cell lines. Overall it was found that styelsamine analogues were stronger DNA binders, with the natural products styelsamines B and D having particularly high affinity. In comparison the cystodytin iminoquinone alkaloids showed lower affinity for DNA, but were just as active as styelsamine analogues at inhibiting proliferation of tumor cells in vitro. Whole cell activity of both styelsamines and cystodytins correlated with lipophilicity, with the most potent growth inhibition properties being associated with alkaloids from both series with $\operatorname{cog} \mathrm{P} \sim 4.0-4.5$. These results will direct future efforts to optimize the antiproliferative activity of this class of natural products.

\section{Acknowledgments}

We thank the University of Auckland for funding and DTP branch of the NCI for antitumor testing.

\section{References}

1. Molinski, T.F. Marine pyridoacridine alkaloids: Structure, synthesis, and biological chemistry. Chem. Rev. 1993, 93, 1825-1838.

2. Kobayashi, J.; Cheng, J.-F.; Wälchli, M.R.; Nakamura, H.; Hirata, Y.; Sasaki, T.; Ohizumi, Y. Cystodytins A, B, and C, novel tetracyclic aromatic alkaloids with potent antineoplastic activity from the Okinawan tunicate Cystodytes dellechiajei. J. Org. Chem. 1988, 53, 1800-1804. 
3. Kobayashi, J.; Tsuda, M.; Tanabe, A.; Ishibashi, M.; Cheng, J.-F.; Yamamura, S.; Sasaki, T. Cystodytins D-I, new cytotoxic tetracyclic aromatic alkaloids from the Okinawan marine tunicate Cystodytes dellechiajei. J. Nat. Prod. 1991, 54, 1634-1638.

4. McDonald, L.A.; Eldredge, G.S.; Barrows, L.R.; Ireland, C.M. Inhibition of topoisomerase II catalytic activity by pyridoacridine alkaloids from a Cystodytes sp. ascidian: A mechanism for the apparent intercalator-induced inhibition of topoisomerase II. J. Med. Chem. 1994, 37, 3819-3827.

5. Appleton, D.R.; Pearce, A.N.; Lambert, G.; Babcock, R.C.; Copp, B.R. Isodiplamine, cystodytin $\mathrm{K}$ and lissoclinidine: Novel bioactive alkaloids from the New Zealand ascidian Lissoclinum notti. Tetrahedron 2002, 58, 9779-9783.

6. Copp, B.R.; Jompa, J.; Tahir, A.; Ireland, C.M. Styelsamines A-D: New tetracyclic pyridoacridine alkaloids from the Indonesian ascidian Eusynstyela latericius. J. Org. Chem. 1998, 63, 8024-8026.

7. Skyler, D.; Heathcock, C.H. The pyridoacridine family tree: A useful scheme for designing synthesis and predicting undiscovered natural products. J. Nat. Prod. 2002, 65, 1573-1581.

8. Bry, D.; Banaigs, B.; Long, C.; Bontemps, N. New pyridoacridine alkaloids from the purple morph of the ascidian Cystodytes dellechiajei. Tetrahedron Lett. 2011, 52, 3041-3044.

9. Marshall, K.M.; Barrows, L.R. Biological activities of pyridoacridines. Nat. Prod. Rep. 2004, 21, 731-751.

10. Skyler, D.; Heathcock, C.H. A simple biomimetic synthesis of styelsamine B. Org. Lett. 2001, 3, 4323-4324.

11. Rudi, A.; Kashman, Y. Six new alkaloids from the purple Red Sea tunicate Eudistoma sp. J. Org. Chem. 1989, 54, 5331-5337.

12. Plubrukarn, A.; Davidson, B.S. Arnoamines A and B, new cytotoxic pentacyclic pyridoacridine alkaloids from the ascidian Cystodytes sp. J. Org. Chem. 1998, 63, 1657-1659.

13. Bouffier, L.; Baldeyrou, B.; Hildebrand, M.-P.; Lansiaux, A.; David-Cordonnier, M.-H.; Carrez, D.; Croisy, A.; Renaudet, O.; Dumya, P.; Demeunynck, M. Amino- and glycoconjugates of pyrido[4,3,2-kl]acridine. Synthesis, anti-tumor activity, and DNA binding. Bioorg. Med. Chem. 2006, 14, 7520-7530.

14. Bouffier, L.; Gosse, I.; Demeunynck, M.; Mailley, P. Electrochemistry and bioactivity relationship of 6-substituted-4H-pyrido[4,3,2-kl]acridin-4-one antitumor drug candidates. Bioelectrochemistry 2012, 88, 103-109.

15. LePecq, J.B.; Paoletti, C. A fluorescent complex between ethidium bromide and nucleic acids. J. Mol. Biol. 1967, 27, 87-106.

16. Jenkins, T.C. Optical absorbance and fluorescence techniques for measuring DNA-drug interaction. In Drug-DNA Interaction Protocols; Fox, K.R., Ed.; Humana Press: Totowa, NJ, USA, 1997; pp. 195-218.

17. Tetko, I.V.; Gasteiger, J.; Todeschini, R.; Mauri, A.; Livingstone, D.; Ertl, P.; Palyulin, V.A.; Radchenko, E.V.; Zefirov, N.S.; Makarenko, A.S.; Tanchuk, V.Y.; Prokopenko, V.V. Virtual computational chemistry laboratory_design and description. J. Comput. Aid. Mol. Des. 2005, 19, 453-463.

18. ALOGPS 2.1; Virtual Computational Chemistry Laboratory: Neuherberg, Germany, 2005. 
19. Snell, R.H.; Woodward, R.L.; Willis, M.C. Catalytic enantioselective total synthesis of hodgkinsine B. Angew. Chem. Int. Ed. 2011, 50, 9116-9119.

20. Nakagawa, M.; Okajima, H.; Hino, T. Photosensitized oxygenation of $\mathrm{N}_{\mathrm{b}}$-methoxycarbonyl tryptamines. A new pathway to kynurenine derivatives. J. Am. Chem. Soc. 1977, 99, 4424-4429.

21. Weissbach, H.; Smith, T.E.; Daly, J.W.; Witkop, B.; Udenfriend, S. A rapid spectrophotometric assay of monoamine oxidase based on the rate of disappearance of kynuramine. J. Biol. Chem. 1960, 235, 1160-1163.

22. Johannes, M.; Altmann, K.-H. A ring-closing metathesis-based approach to the synthesis of (+)-tetrabenazine. Org. Lett. 2012, 14, 3752-3755.

23. Minor, D.L.; Wyrick, S.D.; Charifson, P.S.; Watts, V.J.; Nichols, D.E.; Mailman, R.B. Synthesis and molecular modeling of 1-phenyl-1,2,3,4-tetrahydroisoquinolines and related 5,6,8,9-Tetrahydro-13b $H$-dibenzo[ $a, h]$ quinolizines as $\mathrm{D}_{1}$ dopamine antagonists. J. Med. Chem. 1994, 37, 4317-4328.

24. Nagubandi, S.; Fodor, G. The mechanism of the Bischler-Napieralski reaction. J. Heterocycl. Chem.1980, 17, 1457-1463.

25. Burke, T.R.; Fesen, M.R.; Mazumder, A.; Wang, J.; Carothers, A.M.; Grunberger, D.; Driscoll, J.; Kohn, K.; Pommier, Y. Hydroxylated aromatic inhibitors of HIV-1 integrase. J. Med. Chem. 1995, 38, 4171-4178.

26. Dang, H.T.; Kang, G.J.; Yoo, E.S.; Hong, J.; Choi, J.S.; Kim, H.S.; Chung, H.Y.; Jung, J.H. Evaluation of endogenous fatty acid amides and their synthetic analogues as potential anti-inflammatory leads. Bioorg. Med. Chem. 2011, 19, 1520-1527.

27. Developmental Therapeutics Program NCI/NIH. Available online: http://dtp.nci.nih.gov/ (accessed on 16 November 2012).

(C) 2013 by the authors; licensee MDPI, Basel, Switzerland. This article is an open access article distributed under the terms and conditions of the Creative Commons Attribution license (http://creativecommons.org/licenses/by/3.0/). 